\title{
Integrating Habit into UTAUT: The Chinese eBay Case
}

\author{
Seppo Pahnila \\ Department of Information Processing Science, \\ University of Oulu, Finland \\ seppo.pahnila@oulu.fi \\ Mikko Siponen \\ Department of Information Processing Science, \\ University of Oulu, Finland \\ mikko.siponen@oulu.fi \\ Xiaosong Zheng \\ Sydney Institute of Language and Commerce, \\ Shanghai University, China \\ xiaosong.zheng@shu.edu.cn
}

\begin{abstract}
Technology acceptance has received considerable attention in the Information Systems (IS) literature. Accordingly, a number of theories and models have been advanced to explain technology acceptance. Recently, the Unified Theory of Acceptance and Use of Technology (UTAUT) has been put forward on the basis of integrating eight technology-acceptance models. The developers of UTAUT have suggested that future research should extend UTAUT by integrating habit into it in order to increase the explanatory value of UTAUT. To date, we have found no studies that have attempted to integrate habit into UTAUT. As a step in remedying this gap in the literature, we first developed such an integrated model and then tested it $(N=180)$. Our results support the integration: the extended UTAUT provides better explanatory value than UTAUT without habit. Implications for research and practice are suggested based on the findings.
\end{abstract}

Keywords: Habit, Behavioral frequency, Goal-oriented behavior, Unified theory of acceptance and use of technology (UTAUT). 
Integrating Habit into UTAUT: The Chinese eBay Case / Pahnila et al.

\section{Introduction}

The use of technology is a well-studied phenomenon in Information Systems (IS) and a number of models have been developed in this area. Recently, the Unified Theory of Acceptance and Use of Technology (UTAUT) has been advanced, based on integrating eight models of IT acceptance (Venkatesh et al., 2003). While a number of studies have tested UTAUT in different contexts, only a few studies have tried to extend UTAUT; for example, by adding personality theories (Wang and Yang, 2005). Against this backdrop, Venkatesh et al. (2003) have suggested that future research should investigate the role of habit in UTAUT. Such studies are important, because one classical aim of the scientific research is to increase the explanatory power of the existing models (Akers and Sellers, 2004). Despite this, we have found no studies that have accomplished this by integrating habit into UTAUT.

As a first step in remedying this gap in the literature, we integrated habit into UTAUT and then tested the model in a new context by applying it to explain the use of the Chinese eBay, called Tao Bao. Tao Bao is the most popular C2C, B2C auction site in China, where sellers-individuals, retailers, and wholesalers-sell items to consumers. Items include a wide range of goods such as furniture, electronics, clothes, and building materials. Taobao.com had 170 million registered users at the end of 2009 and transaction value on the site in 2009 reached 200 billion yuan (US\$ 29 billion) (Networkworld, 2010). It is the eleventh most successful website in the world and makes more money than almost all US e-commerce sites except Amazon (Walsh, 2010).

By integrating habit into UTAUT, this paper aims to make a number of contributions to the IS literature. First and foremost, this study extends UTAUT by integrating the habit construct into UTAUT, as suggested by Venkatesh et al. (2003). Through this integration, we aim to increase the explanatory value of UTAUT. Such integration is fruitful, given that UTAUT views intention as one of the primary factors in IT acceptance. Although UTAUT is a holistic model in terms of explaining IT acceptance, goal-oriented habit is an important complementary predictor of the reasonedbased UTAUT constructs. Besides the aforementioned key contribution (adding habit to UTAUT), this study also offers two other contributions. The most important of these is the introduction of the self-report habit index by Verplanken and Orbell (2003) to IS ${ }^{1}$. The other involves the testing of the extended UTAUT in a new context by examining how it explains the use of Tao Bao.

The rest of the manuscript is set out as follows. In the second section, we discuss previous work on UTAUT. The third section presents the theoretical framework of the study; namely UTAUT and habit by Verplanken and Orbell (2003). The fourth section discusses the research methods and results. The fifth section discusses the findings and their implications for research and practice. Finally, the sixth section concludes the paper.

\section{Previous Empirical Work on UTAUT}

Since UTAUT was first developed by Venkatesh et al. (2003), several empirical studies have been carried out in different contexts to test UTAUT (see Table 1).

To summarize the findings of the literature review presented in Table 1, most of the studies have applied UTAUT in different contexts and countries. To the best of our knowledge, only four studies (Neufeld et al., 2007; Wang and Yang, 2005; Zhou et al., 2010; Chen, 2011) have attempted to extend UTAUT. Such studies extending extant theories and models are important in order to further increase the explanatory power of these theories and models. Of these studies extending UTAUT, Neufeld et al. (2007) integrated UTAUT with charismatic leadership theory and examined the role of project champions in influencing user adoption. In turn, Wang and Yang (2005) combined the theory of personality traits with UTAUT. However, we have found no existing studies that have attempted to integrate habit into UTAUT. Such integra- 
tion of habit into UTAUT is called for by Venkatesh et al. (2003) in order to further increase the explanatory power of UTAUT. The call for integrating habit into the UTAUT model seems justified, given the supportive empirical evidence on habitual and automatic behavior in IS (Limayem et al., 2007) and social psychology (Verplanken and Orbell, 2003).

Following the suggestion by Venkatesh et al. (2003), we first advanced an extended UTAUT model, where habit is integrated into UTAUT. Then we tested the extended model in a new context and new culture by applying it to explain the use of the Chinese eBay (Tao Bao). Next, we discuss the extended UTAUT model.

\section{Theoretical Framework}

The theoretical model presented in this paper combines studies of habits by Verplanken and Orbell (2003) and studies of UTAUT by Venkatesh et al. (2003) (see Figure 1). UTAUT was developed by comparing and integrating eight IT acceptance models (Venkatesh et al., 2003). While UTAUT can be regarded as holistic, it does not cover habitual behavior. Indeed, Venkatesh et al. (2003) noted the importance of habit, suggesting that future research should investigate the role of habit in UTAUT. To be more precise, Venkatesh et al. (2003) noted that habit should be studied with UTAUT, as sustained use behavior may not be the result of deliberated cognitions but may simply be routinized or automatic responses to stimuli (i.e., habit). Venkatesh et al. (2000) maintain that frequent and consistent use of the same mental processes in particular situations results in automatization, which in turn results in an individual unintentionally making the same choice when faced with the situation again (Venkatesh et al., 2000). In addition, a number of studies in the area of technology acceptance have recognized the potential role of habit in predicting systems' use (Kim et al., 2005; Limayem and Hirt, 2003; Limayem et al., 2007). Accordingly, we extended UTAUT by adding habit to it. This action is called "theory integration," meaning that at least two existing theoretical or conceptual models are combined together. The aim of theory integration is to offer greater comprehensiveness and increased explanatory value compared to each component model alone (Farnworth, 1989). Hence, theory integration is meaningful if the new model can offer increased explanatory power. Against this backdrop, we suggest that habit, or more precisely, the selfreport habit index by Verplanken and Orbell (2003), should be integrated into UTAUT to further increase the explanatory power of UTAUT. Akers and Sellers (2004) and Thornberry (1989) point out the following guidelines for theoretical integration. First, scholars should determine whether the theoretical frameworks to be merged explain the same or similar phenomena, and then they should review the components of both theoretical models. This process has three goals. The first goal is to determine whether the theoretical or conceptual models to be merged contain the same or similar constructs. If they contain the same or similar constructs, then scholars should see if those constructs can be integrated. The other goals are to see whether these theoretical models to be integrated have different constructs and theoretical components, and whether these theoretical or conceptual models explain or predict the same or similar phenomena. Considering UTAUT and habit in the light of these guidelines by Akers and Sellers (2004) and Thornberry (1989), we can easily see that both UTAUT and habit are theoretical models that explain and predict behavior. UTAUT was developed with technology acceptance in mind, while habit is a general theoretical account aimed at explaining any behavior, whether in relation to technology use or not (Verplanken and Orbell, 2003). Hence, keeping in mind the aim of the habit construct, integrating habit into UTAUT is not a problem from the theoretical perspective of habit. For the habit construct, technology acceptance is just one type of behavior that can be habitual. Hence, both theoretical models (UTAUT and habit) can be seen to explain similar phenomena, and there is no conflict in this respect.

From the point of view of reviewing these 


\begin{tabular}{|c|c|c|c|}
\hline 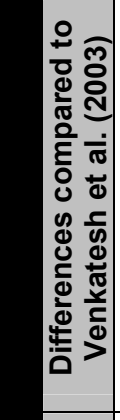 & 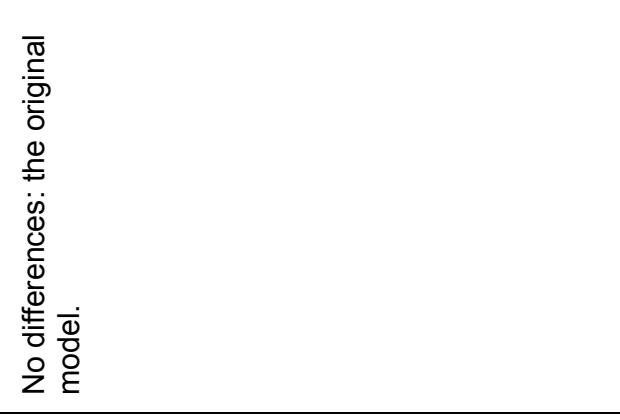 & 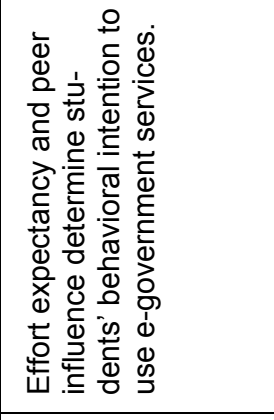 & 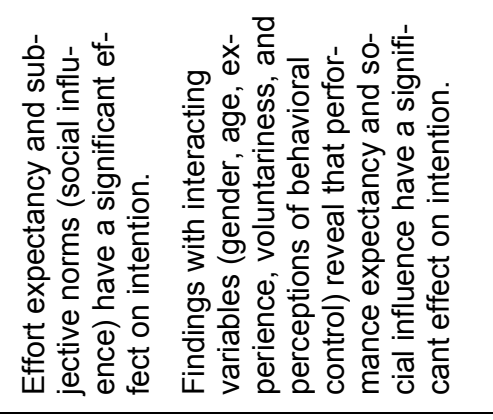 \\
\hline 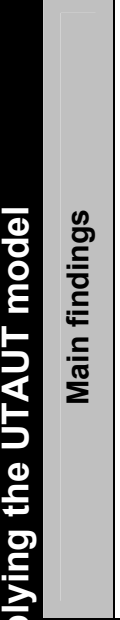 & 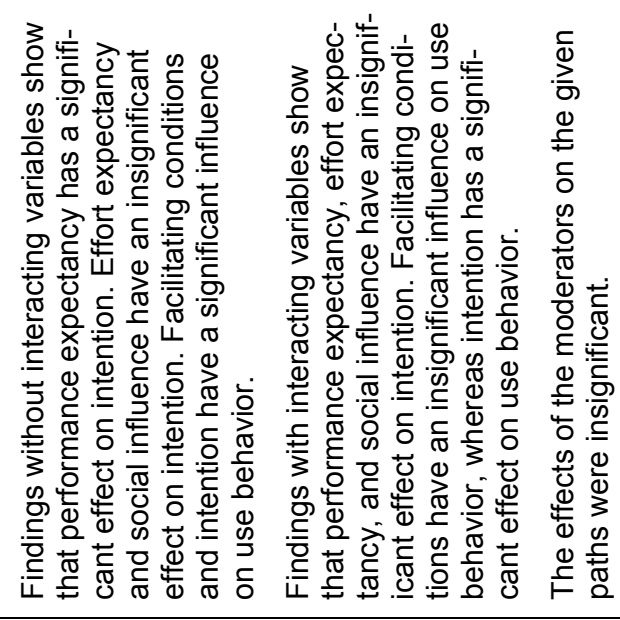 & 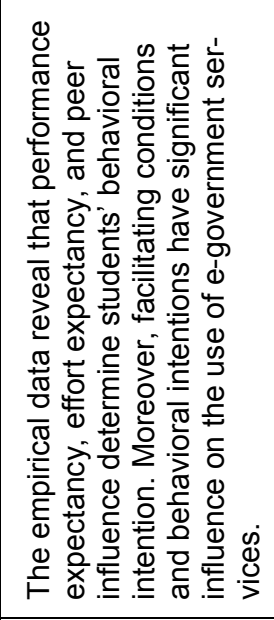 & 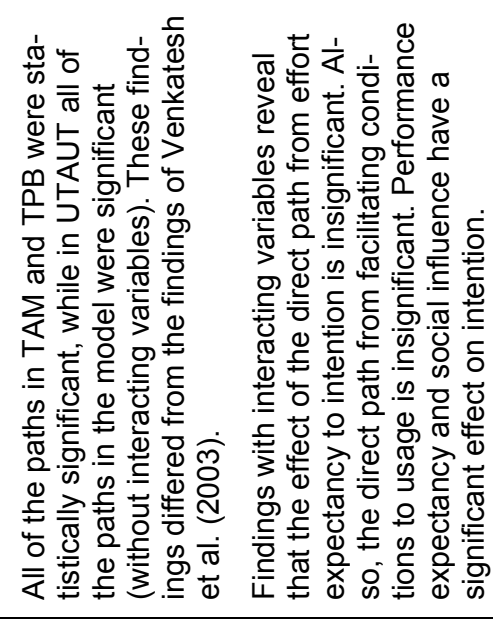 \\
\hline 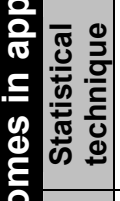 & 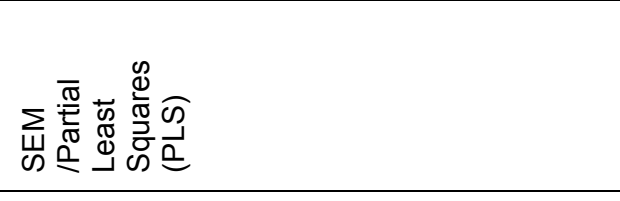 & 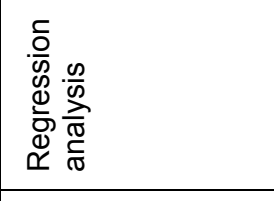 & 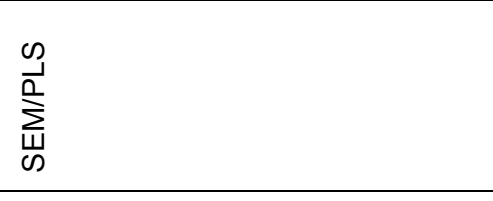 \\
\hline 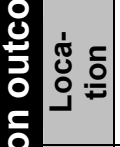 & कీ & 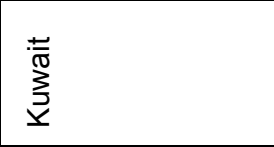 & 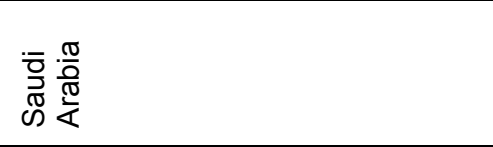 \\
\hline 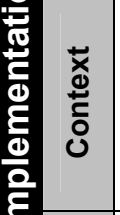 & 产 & 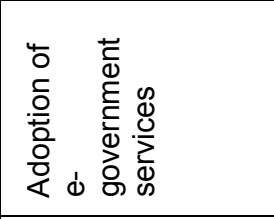 & 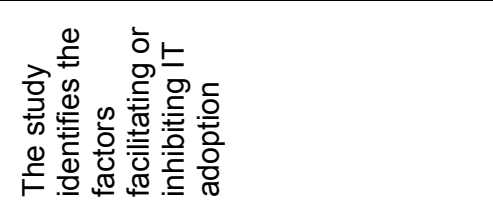 \\
\hline $\begin{array}{l}\frac{0}{0} \\
\text { Еूँ } \\
\text { ஸ็ }\end{array}$ & 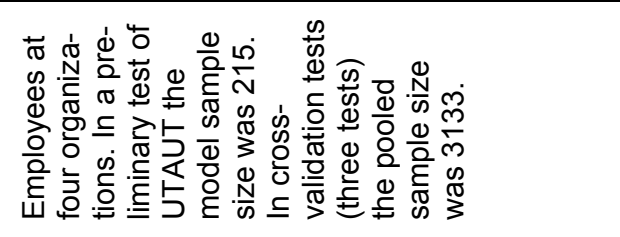 & 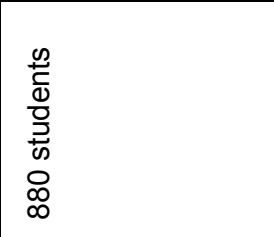 & 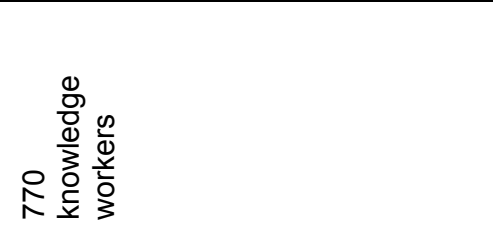 \\
\hline 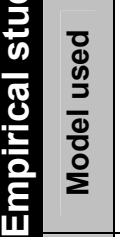 & 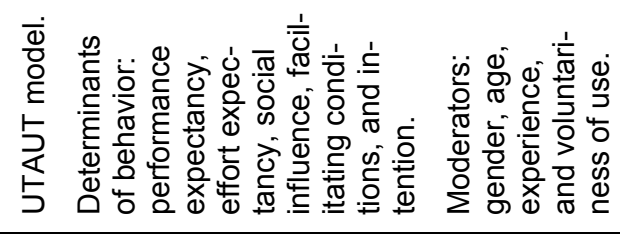 & 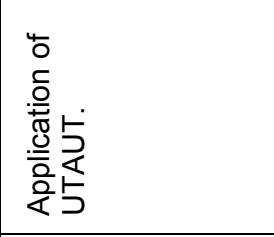 & 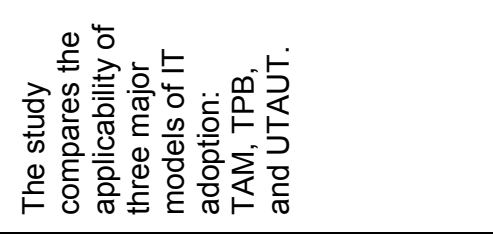 \\
\hline $\begin{array}{l}\text { 高 } \\
\text { 妾 } \\
\end{array}$ & 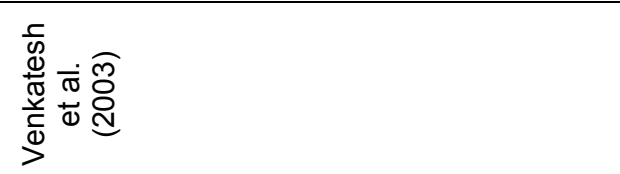 & 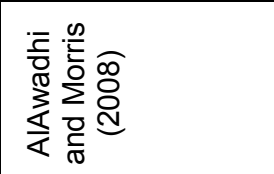 & 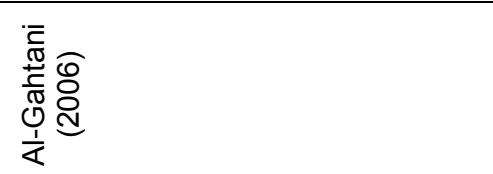 \\
\hline
\end{tabular}




\begin{tabular}{|c|c|c|c|c|}
\hline 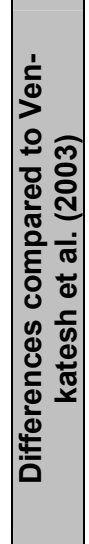 & 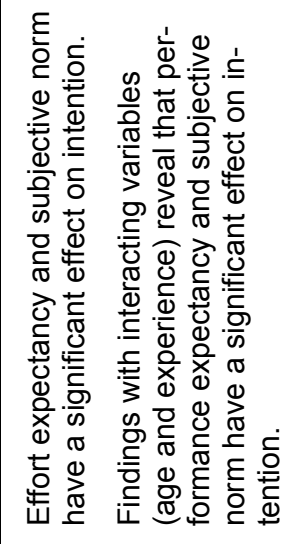 & 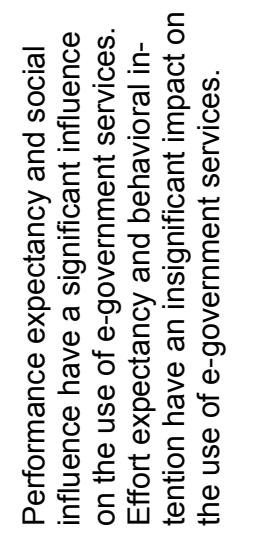 & 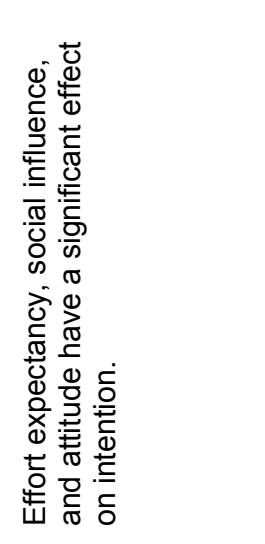 & 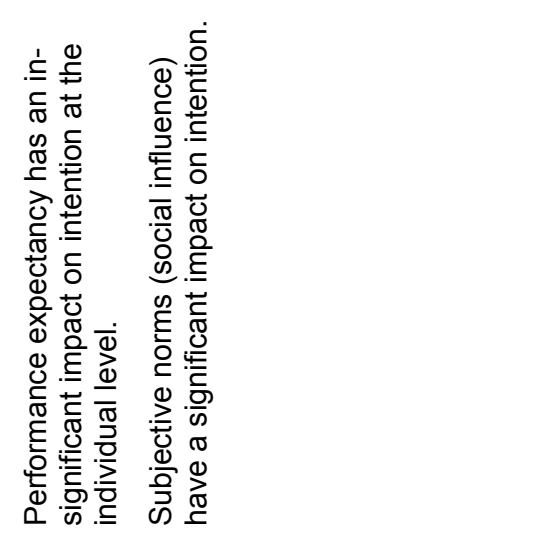 \\
\hline 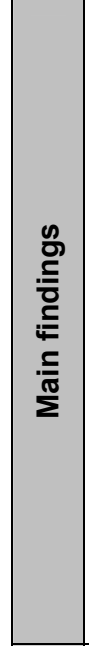 & 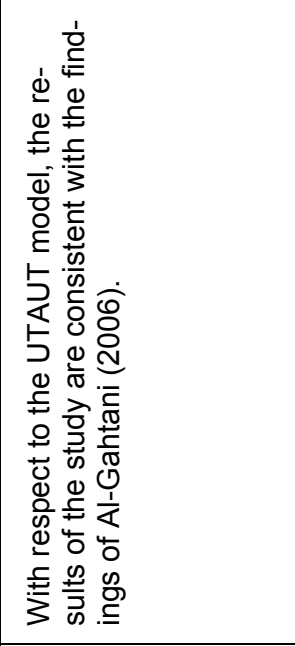 & 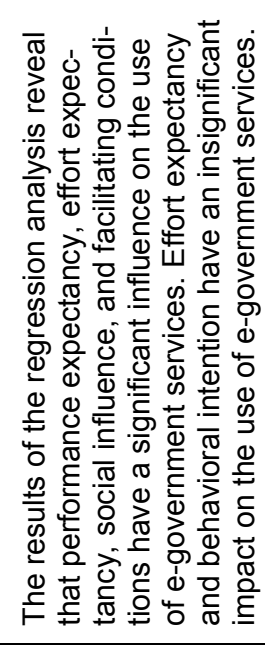 & 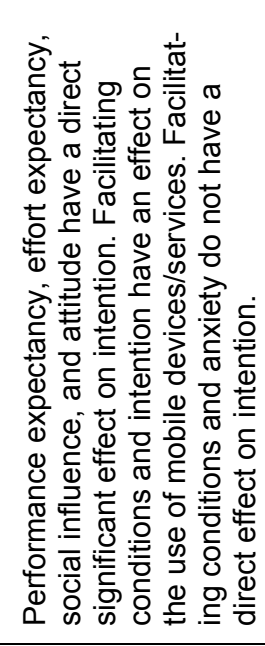 & 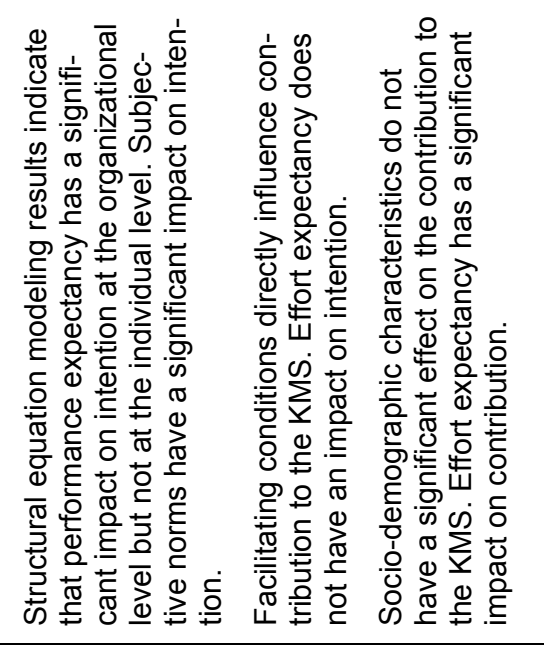 \\
\hline 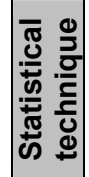 & 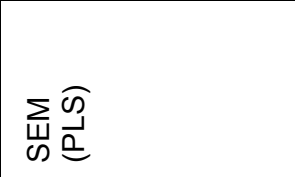 & 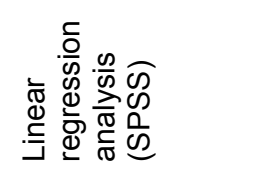 & 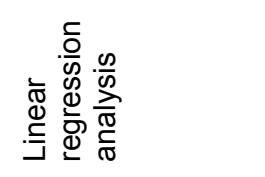 & 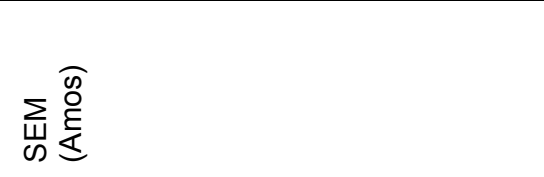 \\
\hline 용 & 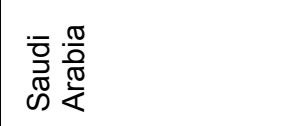 & 票 & $\begin{array}{l}\frac{0}{c} \\
\frac{\pi}{\mathbb{T}} \\
i \frac{1}{\leftarrow}\end{array}$ & 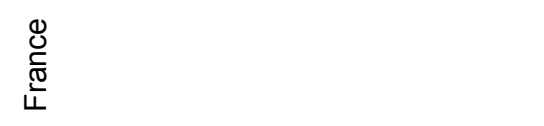 \\
\hline 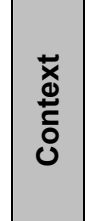 & 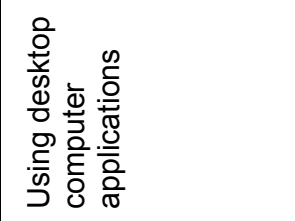 & 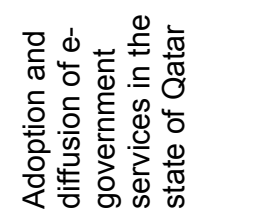 & 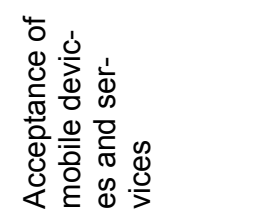 & 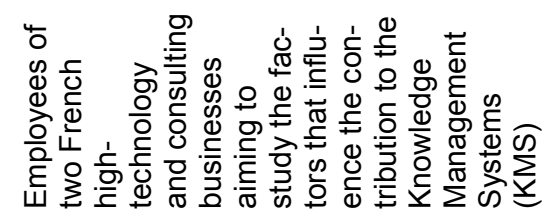 \\
\hline$\frac{\frac{0}{0}}{\frac{0}{E}}$ & $N_{\substack{\frac{8}{0} \\
\frac{0}{3}}}^{\frac{\infty}{2}}$ & 兽 & 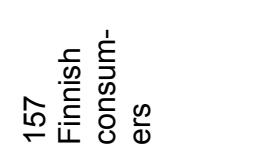 & 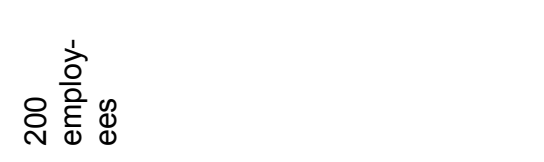 \\
\hline 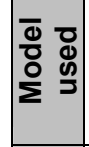 & 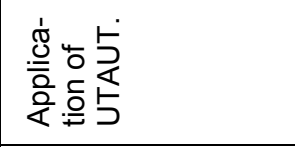 & 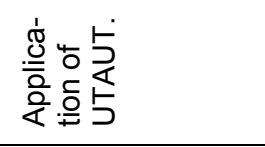 & 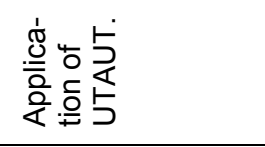 & 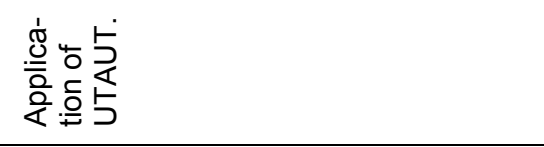 \\
\hline 高 & 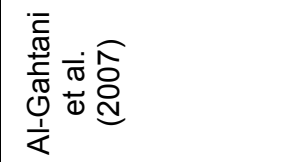 & 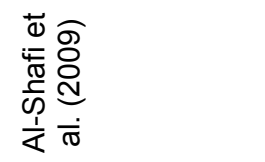 & 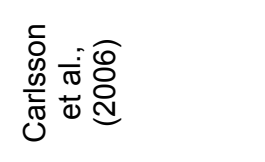 & 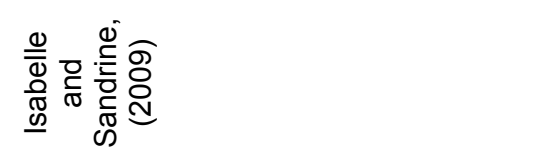 \\
\hline
\end{tabular}


Integrating Habit into UTAUT: The Chinese eBay Case / Pahnila et al.

\begin{tabular}{|c|c|c|c|c|}
\hline 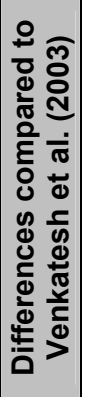 & 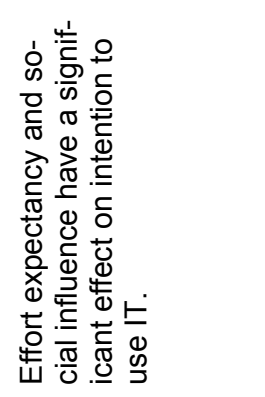 & 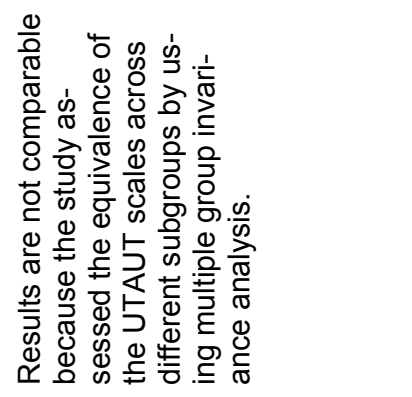 & 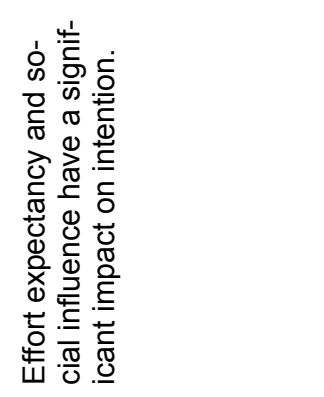 & 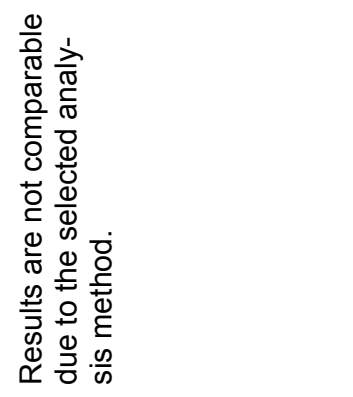 \\
\hline 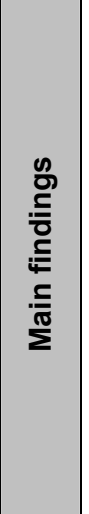 & 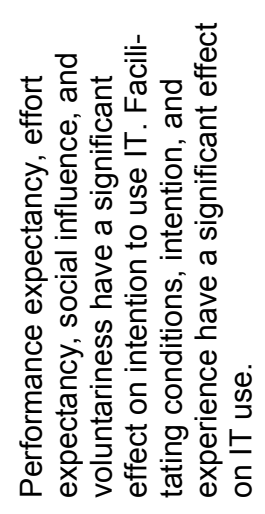 & 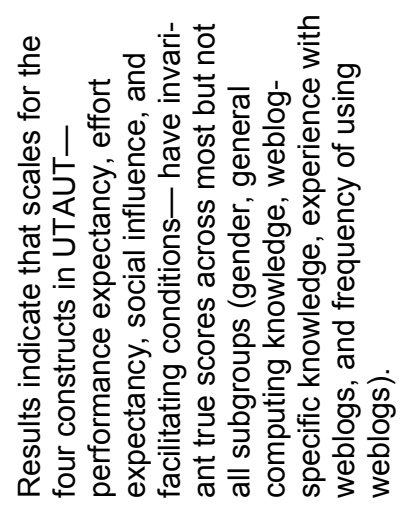 & 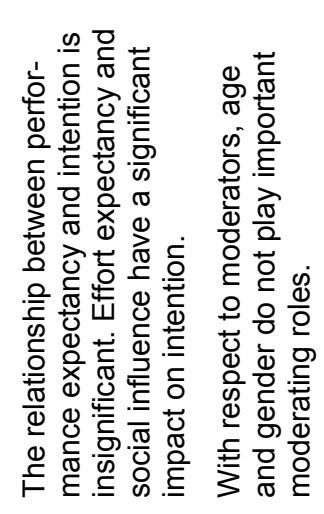 & 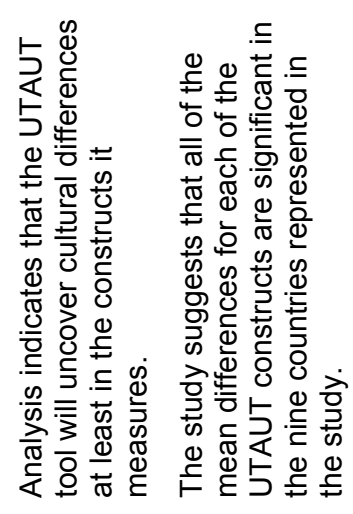 \\
\hline 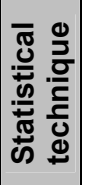 & 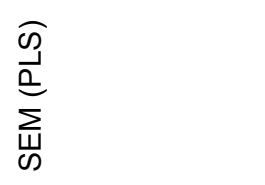 & 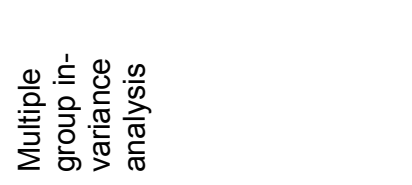 & 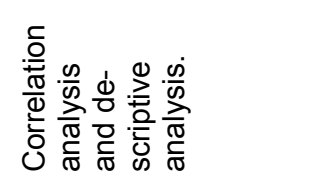 & 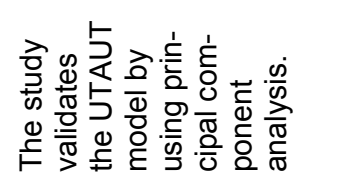 \\
\hline 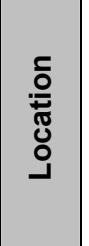 & $\begin{array}{l}\stackrel{ }{\frac{T}{T}} \\
\frac{N}{\bar{T}} \\
\stackrel{F}{F}\end{array}$ & 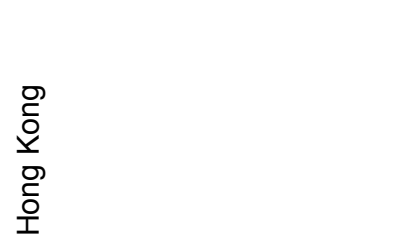 & 吣 & 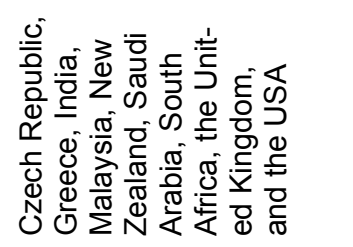 \\
\hline 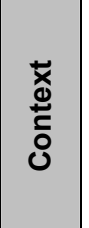 & 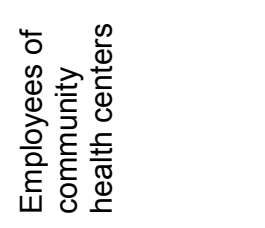 & 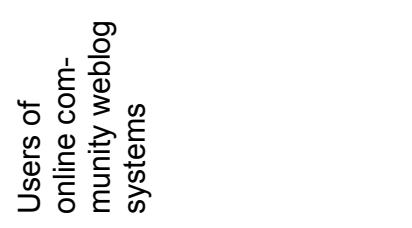 & 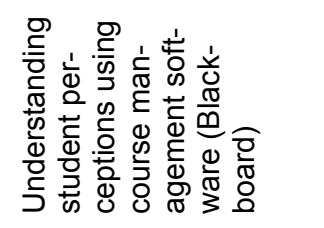 & 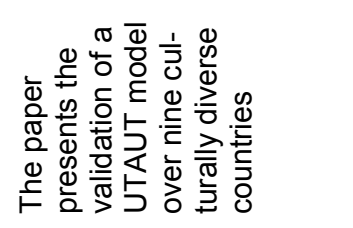 \\
\hline $\begin{array}{l}\frac{0}{0} \\
\frac{\tilde{F}^{\circ}}{\infty}\end{array}$ & $\stackrel{\circ}{\circ}$ & 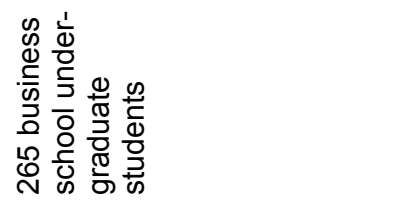 & 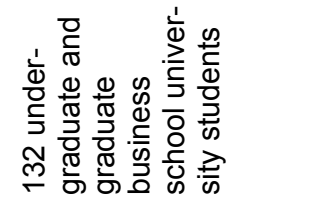 & 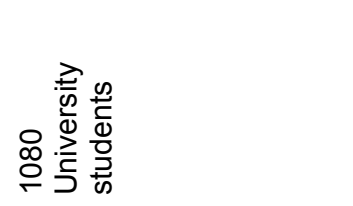 \\
\hline 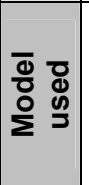 & 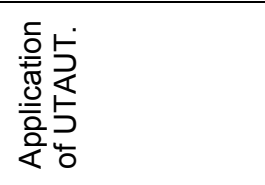 & 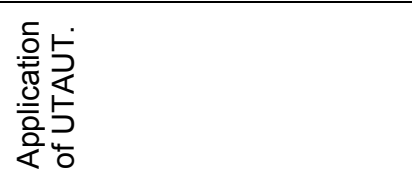 & 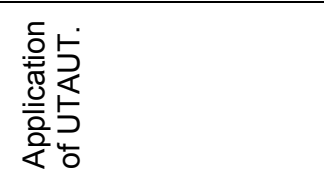 & 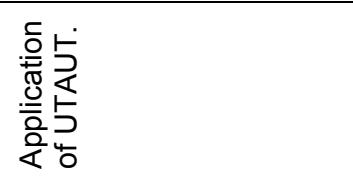 \\
\hline 高 & 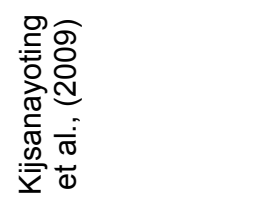 & 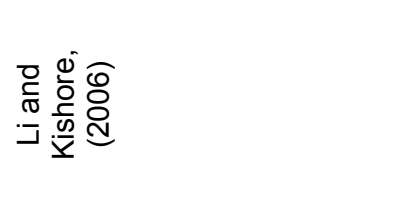 & 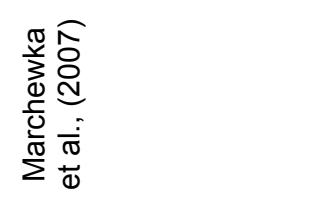 & 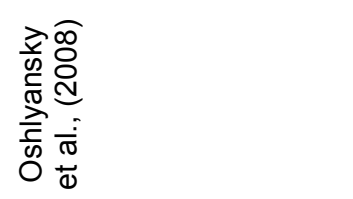 \\
\hline
\end{tabular}


Integrating Habit into UTAUT: The Chinese eBay Case / Pahnila et al.

\begin{tabular}{|c|c|c|c|}
\hline 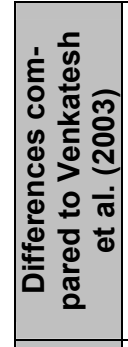 & 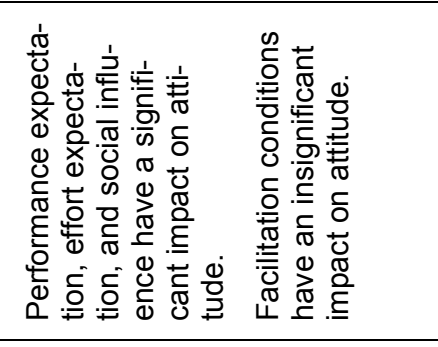 & 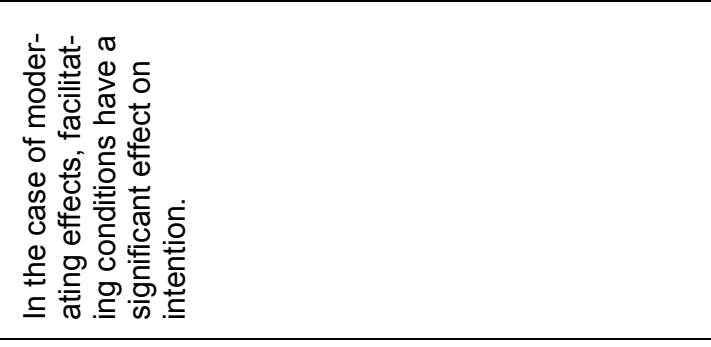 & 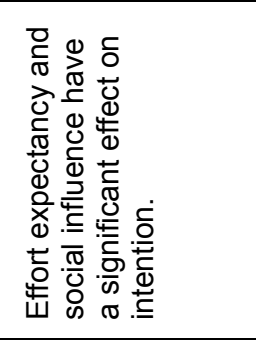 \\
\hline 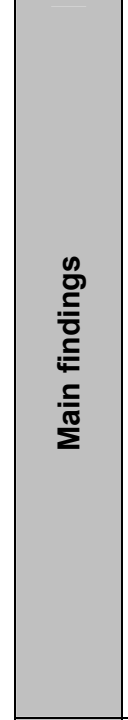 & 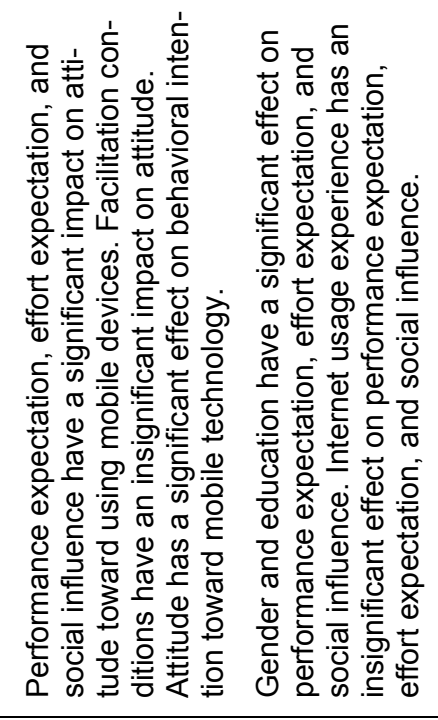 & 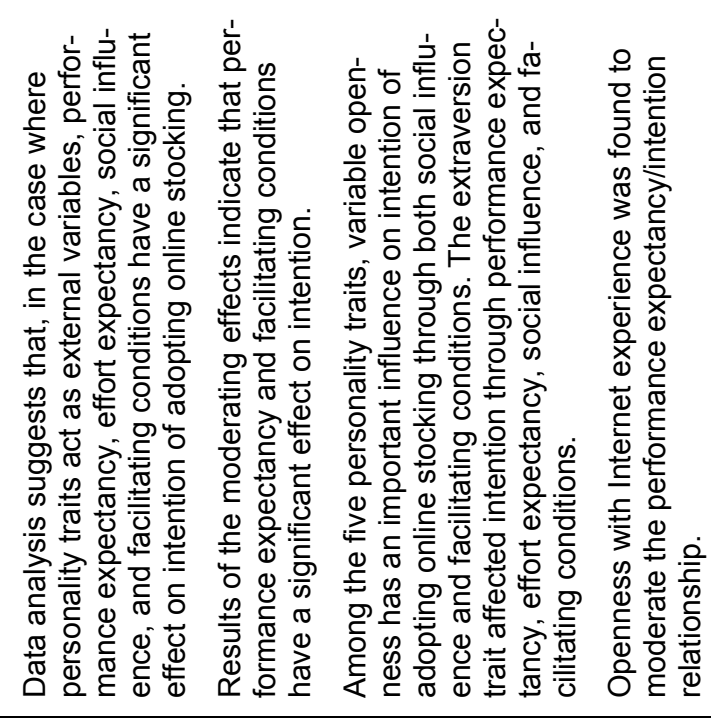 & 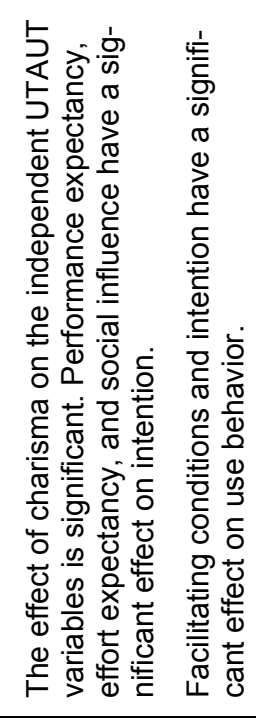 \\
\hline 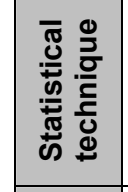 & 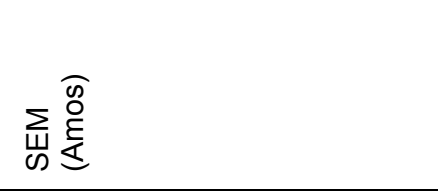 & 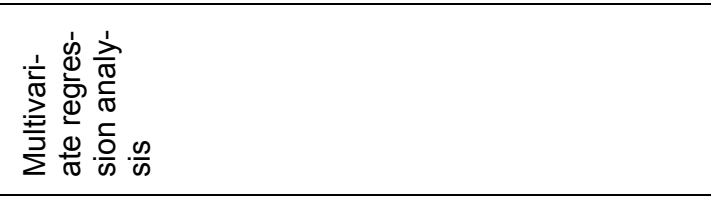 & 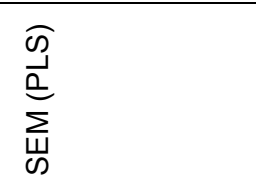 \\
\hline 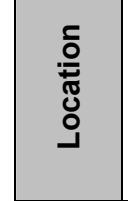 & 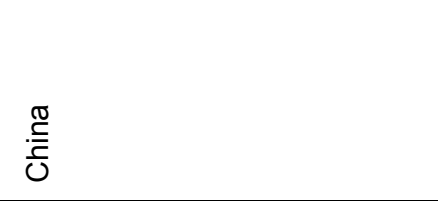 & 葛 & 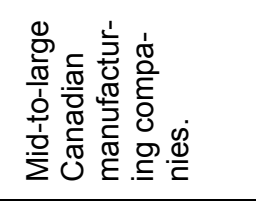 \\
\hline 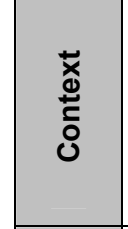 & 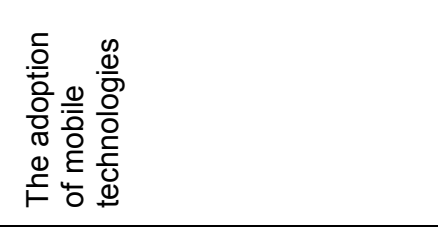 & 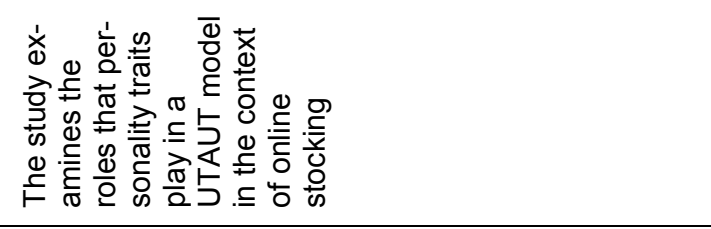 & 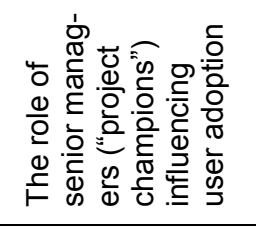 \\
\hline $\begin{array}{l}\frac{0}{0} \\
\text { कू } \\
\text { का }\end{array}$ & 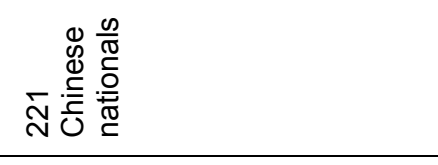 & 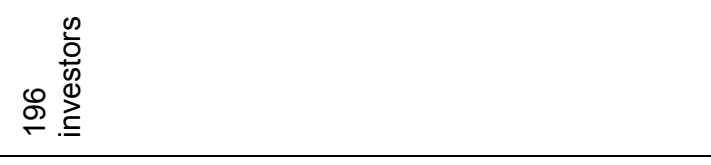 & 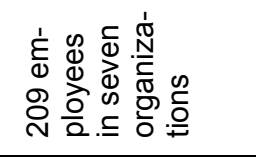 \\
\hline 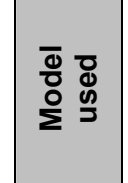 & 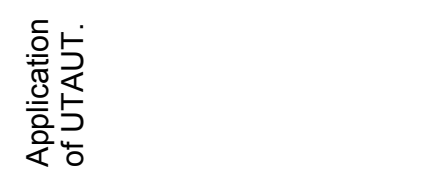 & 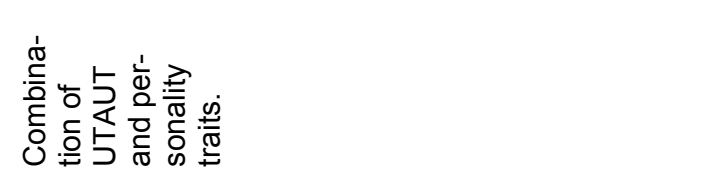 & 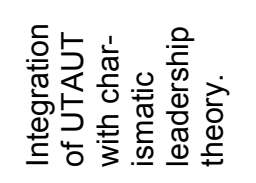 \\
\hline $\begin{array}{l}\text { के } \\
\frac{\dot{s}}{3}\end{array}$ & 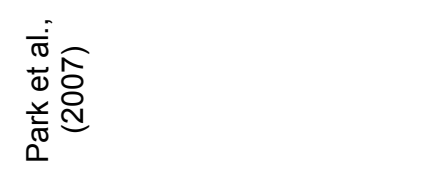 & 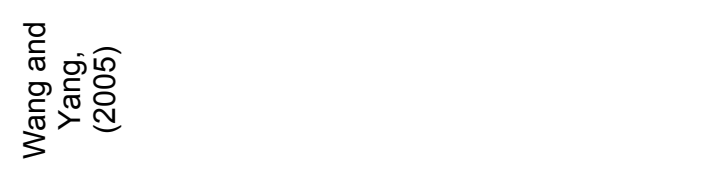 & 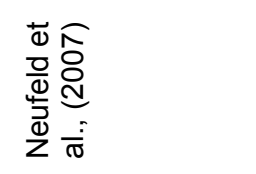 \\
\hline
\end{tabular}


Integrating Habit into UTAUT: The Chinese eBay Case / Pahnila et al.

\begin{tabular}{|c|c|c|}
\hline 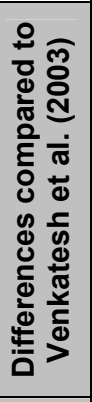 & 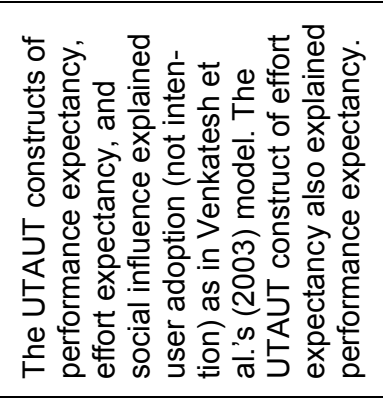 & 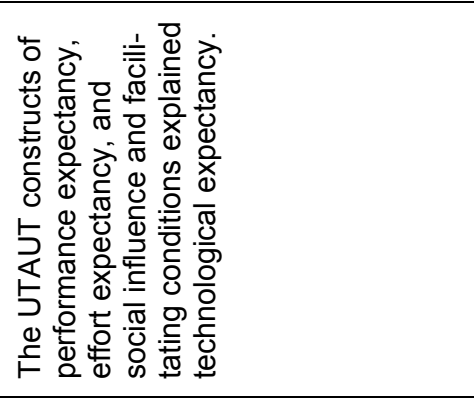 \\
\hline 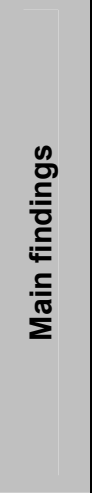 & 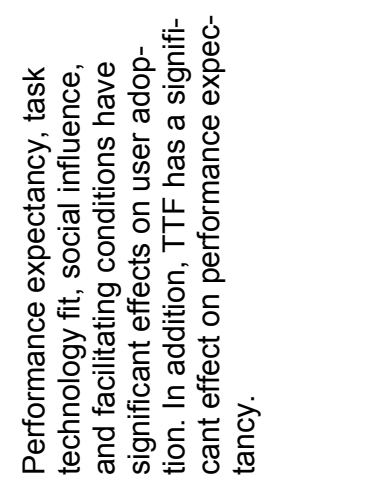 & 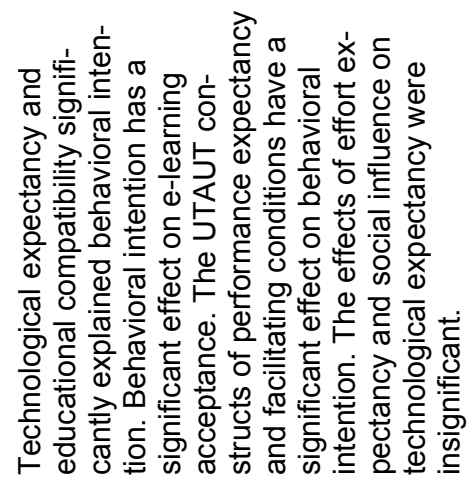 \\
\hline 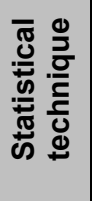 & 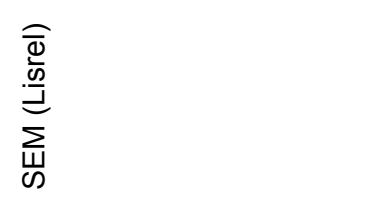 & $\frac{\widehat{a}}{\vec{a}}$ \\
\hline 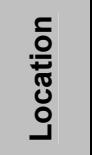 & $\stackrel{\frac{\pi}{\tilde{E}}}{\stackrel{\underline{\underline{J}}}{0}}$ & 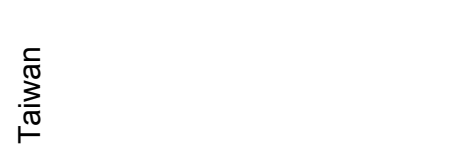 \\
\hline 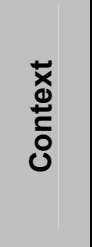 & 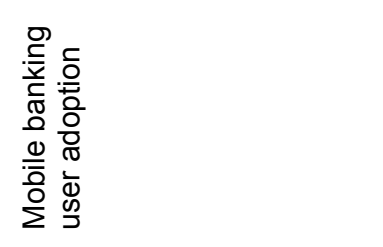 & 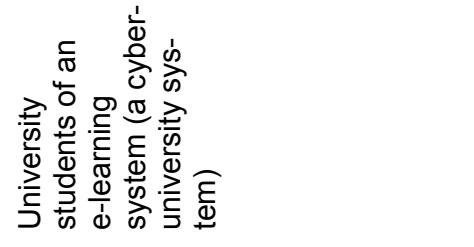 \\
\hline 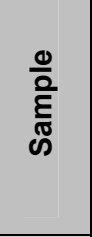 & 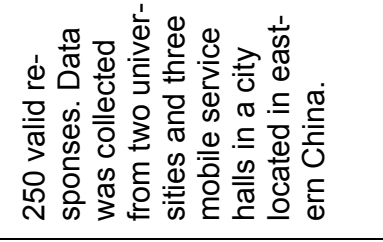 & 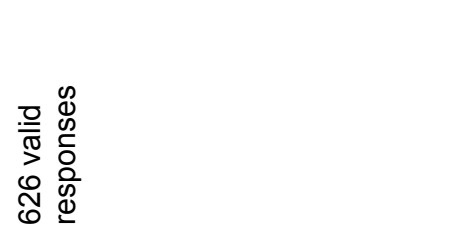 \\
\hline 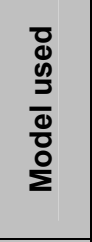 & 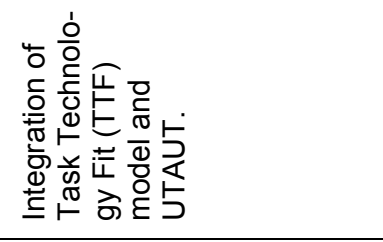 & 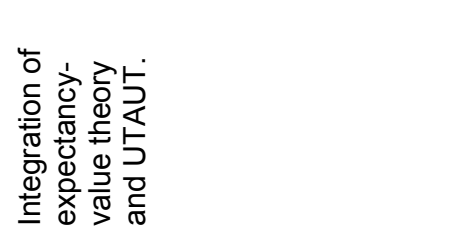 \\
\hline 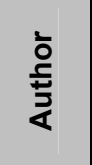 & 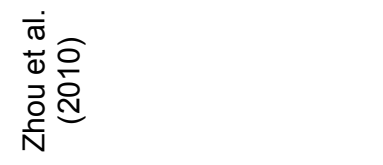 & 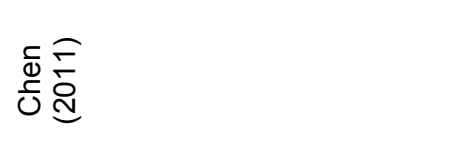 \\
\hline
\end{tabular}


theoretical models for similar components, there are none. Habit focuses on habitual, automatic behavior and it does not include any other components. In turn, UTAUT comprises performance expectancy, effort expectancy, social influence, and facilitating conditions (and anxiety: see below). None of these components of UTAUT focuses on habitual behavior. (For a detailed analysis of the components of UTAUT, see Al-Qeisi, 2009.) This means that there are no common constructs between UTAUT and habit. The only difference between these is that habit offers an alternative way to explain behavior-in our case, technology acceptance. Therefore, keeping in mind the guidelines of Akers and Sellers (2004) and Thornberry (1989), we see that integrating habit into UTAUT is justified and fruitful, and the extended UTAUT model can be expected to increase the explanatory value compared to these two models alone. Next, we describe habit and then UTAUT.

\section{Habit}

A habit is an unconscious or automatic behavior, as opposed to an intention, or conscious behavior (Limayem and Hirt, 2003; Ortiz de Guinea and Markus, 2009; Triandis, 1980). Habit differs from reflexes in that to become a habit, an activity requires learning that is composed of several factors such as a number of short-term repetitions, reinforcement, clarity of the situation, interest, and ability to learn (Triandis, 1980). Thus, habit is considered as an unconscious construct explaining behavior (Kim and Srivastava, 2007; Morahan-Martin and Schumacher, 2000). A number of alternative theoretical accounts for habit exist. The development of the habit construct can be traced back to Triandis (1980), who suggested that the strength of a habit "can be measured by the frequency of occurrence of behavior." Based on Triandis's model, habits have been found to explain IS usage (Cheung and Limayem, 2005; Limayem and Hirt, 2003). Following this tradition, most habit research has studied the direct influence of habit on behavior (Cheung et al., 2000; Limayem and Hirt, 2003; Limayem et al., 2004; Triandis, 1980) or the moderating effect of habit between the intention-behavior relationship (Limayem et al., 2007; Cheung and Limayem, 2005). The results of these studies suggest that the influence of habit on actual behavior increases in the long run, while the influence of behavioral intention decreases (Limayem and Hirt, 2003) in the long run. In this research, we study the direct effect of habit on behavior, as suggested in previous literature.

"Triandis's school of habit," where a habit is assessed with a measurement of past behavior or behavioral frequency (Brug et al., 2006; Verplanken and Orbell, 2003) such as the well-known model by Triandis (1980), has received criticism. To be more precise, a number of scholars have criticized the use of measures based on past behavior or behavioral frequency. To start with, Brug and his research associates claim that "past behavior only assesses repetition and not the automatic character of habits. If one regards habit strength as a psychological construct, past behavior may not be the best measure" (Brug et al., 2006, p. 78). Verplanken and Orbell concur: "It is unreasonable to accept a measure of past behavior frequency as a measure of habit strength" (Verplanken and Orbell, 2003, pp. 13-15). In line with the aforementioned authors, Ajzen (2002) suggests that the frequency of past behavior, i.e., the number of times that the past behavior has been performed, is not an indicator of habitual behavior. He observes that "whether a frequently performed behavior has or has not habituated is an empirical question, and to answer it we need an independent and validated measure of habit" (Ajzen, 2002, p. 109). To this end, Verplanken and his colleagues developed and validated a self-report index of habit strength. They define habit as "learned sequences of acts that have become automatic responses to specific cues, and are functional in obtaining certain goals or endstates" (Verplanken and Aarts, 1999, p. 104). In this research, we applied a 12-item scale called the self-report habit index, developed and validated by Verplanken and Orbell (2003). In addition to a history of repetition and features of automaticity, this measure 
Integrating Habit into UTAUT: The Chinese eBay Case / Pahnila et al.

also takes into consideration features such as uncontrollability, lack of awareness, and efficiency. According to Verplanken and Orbell (2003), these are features that characterize the experience of habits in everyday life and thus might reflect a sense of identity or personal style. Including these features in a selfreport habit instrument provides a more complete and full account of habit, particularly compared to behavioral frequency habit measures.

One of the advantages of the self-report habit measure is the fact that the measure is not based on behavioral frequency estimates. It can be used to monitor habit strength independent of actual behavioral frequency (Verplanken and Orbell, 2003). Thus, decomposing the automaticity component into behavior that is performed without awareness, that is difficult to control, and that is mentally efficient implies that habit frees up mental resources, which means that habit can be executed in parallel with other activities (Verplanken, 2006). There is another reason we prefer the habit measure of Verplanken and Orbell (2003): it is goal-oriented, which matches with UTAUT, as UTAUT has its origin in the reasoned-oriented models (see Verplanken and Melvik, 2008). The fact that habit as measured by Verplanken and Orbell (2003) is goal-oriented, is supported by Ajzen (2002), who emphasized that conscious control is an important issue that has an effect on habitual behavior. Ajzen (2002) maintained that individuals always use deliberation in their decision to take a given action. In this respect, Verplanken et al. (1997) and Verplanken and Melvik (2008) emphasized that when behavior is performed repeatedly and becomes habitual, it may lose its reasonedbased antecedents. IS research also supports this. Ortiz de Guinea and Markus (2009) suggested that one environmental cue that triggers habitual behavior is a task that the individual is required to perform such as making purchases from a familiar online store. Hence, rather than reasoning, habitual behavior is based on goal-oriented behavior (Ortiz de Guinea and Markus, 2009).
As prior research suggests, habit is more goal-oriented than reasoned-oriented. Individuals are able to perform a task based on their past experience. A general finding is that past behavior predicts future behavior. One possible explanation for this is habit, which may become a stronger trigger of future behavior than attitudes and intentions (Verplanken, 2006). We believe that, in the online, e-shop environment, goal-directed behavior plays an important role and is one of the driving forces that affect the individual's behavior. Drawing upon the aforementioned discussion, we posit:

H1. Self-report habits will positively influence on the actual use of Tao Bao.

\section{UTAUT}

UTAUT comprises performance expectancy, effort expectancy, social influence, and facilitating conditions. For detailed analysis of these constructs, see Al-Qeisi (2009). Performance expectancy in UTAUT refers to the concept of which system helps the user to obtain better job performance. Venkatesh et al. (2003) integrated constructs into the UTAUT model from other models, which characterize performance expectancy; namely compatibility, perceived usefulness, and relative advantage. As discussed earlier, several acceptance studies have shown that performance expectancy has a significant influence on intention. The information system is expected to be "capable of being used advantageously" (Davis, 1989). Thus, perceived usefulness is system specific; improving the functionality of the system enhances the system's usefulness (Davis, 1993). The compatibility of the innovation (here, Tao Bao) reflects "the degree to which an innovation is perceived as consistent with the existent values, past experiences, and needs of the potential adopter" (Rogers, 1995). It implies what people feel or think about technology, and it also implies compatibility with what people do (Tornatzky and Klein, 1982). In the case of Tao Bao, users are not expected to receive any gains in job performance. Rather, we assume they believe that eBay enables them to perform business faster than tradi- 
tional ways of selling and buying things. Hence, we hypothesize that:

H2. Performance expectancy will have a significant influence on intention to use Tao Bao.

Effort expectancy in UTAUT refers to the ease of use associated with using the system. Perceived ease of use emphasizes a person's belief that using a particular system does not demand extra effort. Davis (1989) asserts that an application perceived to be easier to use than another is more likely to be accepted by users. We believe that, consistent with the technology-acceptance research (Venkatesh et al., 2003), this component is also relevant for considering the use of Tao Bao, because if the system is difficult to use, users may not use it. Hence, we hypothesize that:

H3. Effort expectancy will have a significant influence on intention to use Tao Bao.

Social influence refers to whether and how one perceives that persons who are important to him or her encourage the use of the system. Here the idea is that individuals' behaviors are influenced by their perception of how others view them if they use a system. The pressure of others may have an influence on the acceptance of the notion that information influencing those individuals creates their behavior toward the system based on their interaction with each other. Thus, it is evident that membership in a social environment has an influence on the adoption of the information system. As discussed earlier, the effect of social influence on intention to use technology has been shown to be significant in several previous acceptance studies. Following UTAUT, we see that social influence has an influence on intention. Hence, we hypothesize that:

H4. Social influence will have a significant influence on intention to use Tao Bao.

UTAUT's facilitating conditions' construct captures the perceived behavior control concept, the facilitating conditions' concept, and compatibility. Facilitating conditions means the existence of support for using the system.
In UTAUT, these are interpreted as organizational and technical support for the use of a system (Venkatesh et al., 2003).

Facilitating conditions refers to perceptions of internal and external constraints on behavior. It tries to explain the behavior of individuals in situations where they do not have volitional control over the behavior in question. When the situation is not under an individual's control-for example, if it is dependent on the decisions of other people-human behavior cannot be predicted from intentions alone (Ajzen, 2002). The more resources and opportunities individuals believe they possess and the fewer obstacles they expect, the stronger is their perceived control over their own behavior. It is likely that an individual with high behavioral control will also have a stronger ability to perform a particular behavior (Ajzen, 1991).

In our context, which is a non-organizational context, unlike the context where UTAUT was tested, the facilitating conditions refer to the resources, knowledge, and ability to use Tao Bao. Prior UTAUT research (AIAwadhi and Morris, 2008; Al-Gahtani, 2006; Al-Shafi et al., 2009; Kijsanayoting et al., 2009) has shown that facilitating conditions have an important influence on behavior. Hence, we hypothesize that:

H5. Facilitating conditions will have a significant influence on actual use of Tao Bao.

In addition to the aforementioned constructs (performance expectancy, effort expectancy, and social influence), UTAUT postulates that there are a number of constructs that are not direct determinants of intention; namely selfefficacy and computer anxiety (Venkatesh et al., 2003). "Computer anxiety" refers to computer users' emotional apprehension and resistance to the use of computer technology. It describes, for example, the individual's internal fear or phobia of making mistakes or causing damage when using computers (Sievert, Albritton, et al., 1988). In the context of this research, computer anxiety can be seen to mean that Tao Bao users are apprehensive, intimidated, and are afraid of the scenario that they may lose some important infor- 
Integrating Habit into UTAUT: The Chinese eBay Case / Pahnila et al.

mation through their use of Tao Bao. With respect to computer anxiety, we argue that, in the case of Tao Bao, one should expect a direct effect between computer anxiety and the use of Tao Bao. We rationalize this difference by the fact that the use of eBay-type ecommerce systems, such as Tao Bao, may not only intimidate users, but they might also find that they could be cheated, or that they could lose money or credit-card information if they use the system (see Igbaria and livari, 1995). Hence, we hypothesize:

H6. Anxiety will positively influence on the actual use of Tao Bao.

Following Theory of Reasoned Action (TRA), UTAUT suggests that the intention to use an IS is the best predictor of actual behavior. A number of studies in the IS literature have confirmed this assumption (Davis, 1989; Venkatesh, 2003; Taylor and Todd, 1995).
Hence, we hypothesize:

H7. Intention to use will have a significant influence on actual use of Tao Bao.

\section{Research Methodology and Re- sults}

The reliability of constructs can be improved by using previously validated and tested questions (Straub, 1989; Boudreau et al., 2001). Accordingly, we used items that have been tried and tested by previous studies, as follows. Our UTAUT-related measurements were adapted from a UTAUT study by Venkatesh et al. (2003) (see Table 4). The instruments were measured using a sevenpoint Likert scale (strongly disagree - strongly agree), except that regularity of use and frequency of use were studied by asking about the regularity of use and the frequency

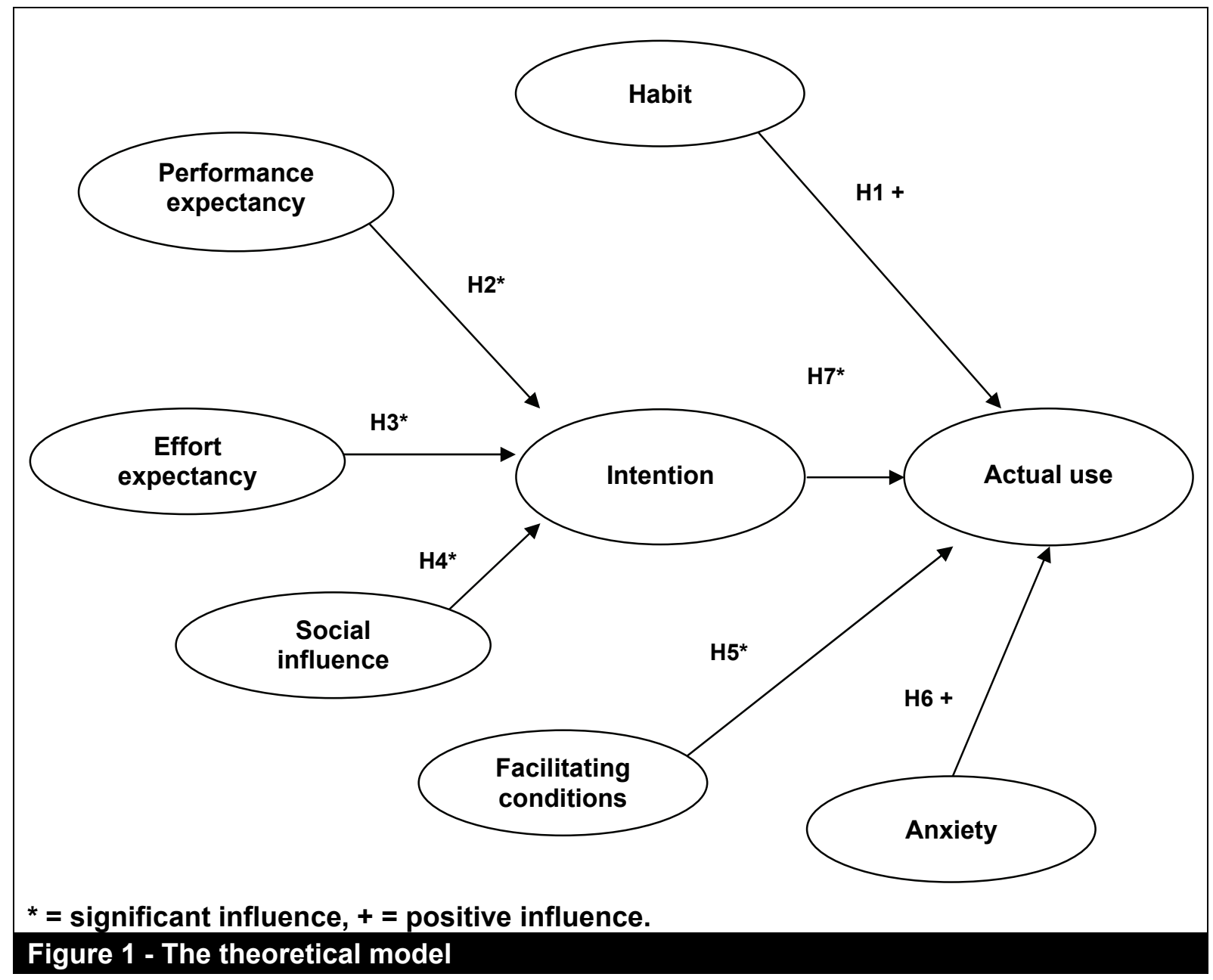




\begin{tabular}{|l|l|l|l|}
\hline \multicolumn{1}{|c|}{$\begin{array}{c}\text { Table 2 - Descriptive statistics of the sample } \\
\text { Measure }\end{array}$} & \multicolumn{1}{c|}{ Items } & \multicolumn{1}{c|}{ Prequency } & Percent \\
\hline \multirow{4}{*}{ Gender } & Male & 167 & 92.7 \\
& Female & 12 & 6.7 \\
& Missing & 1 & 0.6 \\
\hline \multirow{4}{*}{ Age } & $<22$ & 167 & 92.7 \\
& $22-31$ & 12 & 6.7 \\
& $32-41$ & - & \\
& $>41$ & 1 & 0.6 \\
\hline \multirow{5}{*}{ Regularity of Tao Bao use } & Extremely infrequent & 46 & 25.6 \\
& Quite infrequent & 21 & 11.6 \\
& Slightly infrequent & 26 & 14.4 \\
& Neither frequent nor infrequent & 32 & 17.8 \\
& Slightly frequent & 27 & 15.0 \\
& Quite frequent & 14 & 7.8 \\
& Extremely frequent & 14 & 7.8 \\
\hline \multirow{5}{*}{ Frequency of Tao Bao use } & Not at all & 30 & 16.7 \\
& Less than once a month & 48 & 26.7 \\
& About once a month & 32 & 17.7 \\
& 2 or 3 times a month & 34 & 18.9 \\
& Several times a month & 36 & 20.0 \\
\hline
\end{tabular}

of use. These usage measures were based on measures used in previous studies (Moon and Kim, 2001; Igbaria and livari, 1995). Because the measures used in this study had not been tested in the context of Tao Bao, we decided to pre- and pilot-test the measures in this context. All questions were first pretested by five IS scholars in Finland and two IS scholars in China for readability and to ensure that they matched with the theories applied in this study. Then, the instrument was pilot-tested using 40 students at the University of Shanghai, China. Based on their feedback, the content validity of the questions was checked and improved. For the actual data collection, our target group was comprised of students of the business school of the University of Shanghai, China. These were undergraduate, third- and fourth-year bachelor students. It is popular among such Chinese students to use Tao Bao for online shopping. Tao Bao is the most popular C2C auction site in China, where sellersindividuals, retailers, and wholesalers-sell items to consumers. Items include a wide range of goods such as furniture, electronics, clothes, and building materials. Taobao.com had 170 million registered users at the end of 2009 and transaction value on the site in 2009 reached 200 billion yuan (US $\$ 29$ billion) (Networkworld, 2010). It is the eleventh most successful website in the world and makes more money than almost all US e-commerce sites except Amazon (Walsh, 2010). We collected data using paper-form questionnaires and gained 182 responses; the total number of reliable responses was 180 . All students in the classroom took the survey; hence, the response rate was about $100 \%$. The survey was anonymous and it was collected in a classroom before the lecture started. According to the rule of thumb suggested by Chin et al. (1999a), required sample size can be calculated by considering the dependent construct and multiplying the largest number of independent constructs influencing it by 10 . Applying this method, the minimum sample size for our study was $10 \times 4=40$. Thus, the number of responses to the study can be regarded as sufficient. The descriptive statistics for the sample are presented in Table 2.

\section{The measurement model}

One issue that should be taken into consideration when assessing the stability of the estimates and the ability of the variables to predict the dependent measure is the degree of dependence of the independent variables. In an ideal situation, it is desirable that independent variables correlate highly with dependent variables but less with each other (Hair et al., 2006). In order to identify the 
Integrating Habit into UTAUT: The Chinese eBay Case / Pahnila et al.

\begin{tabular}{|c|c|c|c|c|c|c|c|c|c|c|}
\hline Construct & Mean & $\begin{array}{l}\text { Standard } \\
\text { deviation }\end{array}$ & 1. & 2. & 3. & 4. & 5. & 6. & 7. & 8. \\
\hline 1. Use & 3.19 & 1.60 & 0.965 & & & & & & & \\
\hline 2. Intention & 4.81 & 1.06 & 0.454 & 0.883 & & & & & & \\
\hline 3. Habit & 3.75 & 1.17 & 0.521 & 0.576 & 0.784 & & & & & \\
\hline 4. Performance expectancy & 4.15 & 0.95 & 0.236 & 0.556 & 0.598 & 0.759 & & & & \\
\hline 5. Effort expectancy & 4.60 & 0.97 & 0.340 & 0.451 & 0.472 & 0.523 & 0.811 & & & \\
\hline 6. Social influence & 4.00 & 1.19 & 0.261 & 0.356 & 0.215 & 0.219 & 0.304 & 0.792 & & \\
\hline 7. Facilitating conditions & 4.56 & 1.15 & 0.466 & 0.467 & 0.382 & 0.332 & 0.644 & 0.242 & 0.759 & \\
\hline 8. Anxiety & 3.45 & 1.33 & 0.052 & -0.150 & -0.233 & -0.199 & -0.183 & 0.397 & -0.061 & 0.892 \\
\hline
\end{tabular}

threat of multicollinearity, we first assessed the intercorrelations among the factors. All the correlation coefficients were clearly less than 0.80 , which is normally considered as a critical value (Bailey and Pearson, 1983). Second, we measured to what extent each independent variable explains other independent variables by using the SPSS collinearity statistics. The results indicated that the Variance Inflation Factor (VIF) ranged between 1.06 and 2.16, which is below the cutoff threshold VIF value of 5 (Hair et al., 2006). Based on the analyses, it seems that the problem of multicollinearity does not have negative effects on further analyses.

The descriptive statistics of the study were analyzed using the SPSS 16.0 software package. The data analysis was conducted using the Smart PLS structural equation modeling technique (Ringle and Wende, 2005). PLS has been widely used and accepted in different contexts and disciplines (Kleijnen et al., 2007; Limayem et al., 2000; Venkatesh et al., 2003). It is suggested that PLS is a powerful path-modeling procedure because of the minimal demands on measurement scales (i.e., categorical to ratio level indicators can be used in the same model), sample size, and residual distributions (Chin and Newsted, 1999b; Simon and Bruce, 1991).

One of the main reasons component-based PLS was used in this study instead of covariance-based and explanatory SEM techniques, such as Lisrel or Amos, is the starting point of the research. First, the nature of this research is more predictive than confirmatory in terms of theory testing. Second, the selected boot- strapping resampling method freed us from the assumption that the data conforms to a bell-shaped curve.

The mean, standard deviation, and correlations of the constructs are shown in Table 3. The pilot test, as reported before, ensured the content validity of the instrument. Convergent validity was ensured by assessing the factor loadings of the items, Cronbach's alphas, common-method variance, and by calculating Average Variance Extracted (AVE).

Table 4 shows that all of the model items loaded well, exceeding 0.50 (Hair et al., 2006), except in the cases of Intent1, Facicont4, Facicont5, and Anxie3, which were dropped. Item loading clearly below the threshold indicates the existence of excessive error variance, which would probably cause difficulties in further analysis. Facicont5 was slightly below the recommended level, but it was included in the construct because we did not want to lose information, and because the AVE and reliability values were clearly above the threshold. Internal consistency reliability among the items was assessed by calculating Cronbach's alpha. Table 4 shows that this coefficient exceeded the suggested value of 0.60 for all constructs (Hair et al., 2006; Nunnally, 1978). The variance extracted from all the constructs exceeded 0.5 (Fornell and Larcker, 1981; Hair et al., 1998). The composite reliability of all constructs exceeded the suggested value of 0.7 (Nunnally, 1978).

Discriminant validity was assessed by computing the correlations between all pairs of constructs. All correlations were below the threshold value of 0.90 (Hair et al., 1998). 
The square root of the variance extracted was greater than the correlations of the constructs (Table 3). Table 5 presents the crossloadings of the items, which shows that the constructs are different because the respective indicators load most heavily on different factors. Hence, the reliability and validity of the constructs in the model are acceptable.

\section{Common-method bias}

The collected data was based on a self-report questionnaire that used the same questionnaire during the same period. There is a concern that the measurement method may cause systematic measurement error and common-method variance, which may bias the estimates of the relationship among the theoretical constructs. Harman's single-factor test is one of the most widely used techniques for assessing common-method variance (Podsakoff et al., 2003). This test assumes that if a substantial amount of common-method variance is present, then either (a) a single factor will emerge from the factor analysis or (b) one general factor will account for the majority of the covariance among the measures (Malhotra et al., 2006; Pod sakoff et al., 2003; Tiwana et al., 2009).

We conducted Harman's single-factor test, wherein all eight variables were entered into an exploratory factor analysis examining the unrotated factor solution to determine the number of factors that are necessary to account for the variance in the variables. The unrotated, principal-component factor analysis revealed the presence of eight distinct factors with an eigenvalue of greater than 1.0, rather than a single factor. The eight factors together accounted for $73.2 \%$ of the total variance. The first factor accounted for $33.7 \%$ of the variance and the second factor accounted for $10.6 \%$ of the variance. Thus, the results reveal that the common-method variance is not of great concern.

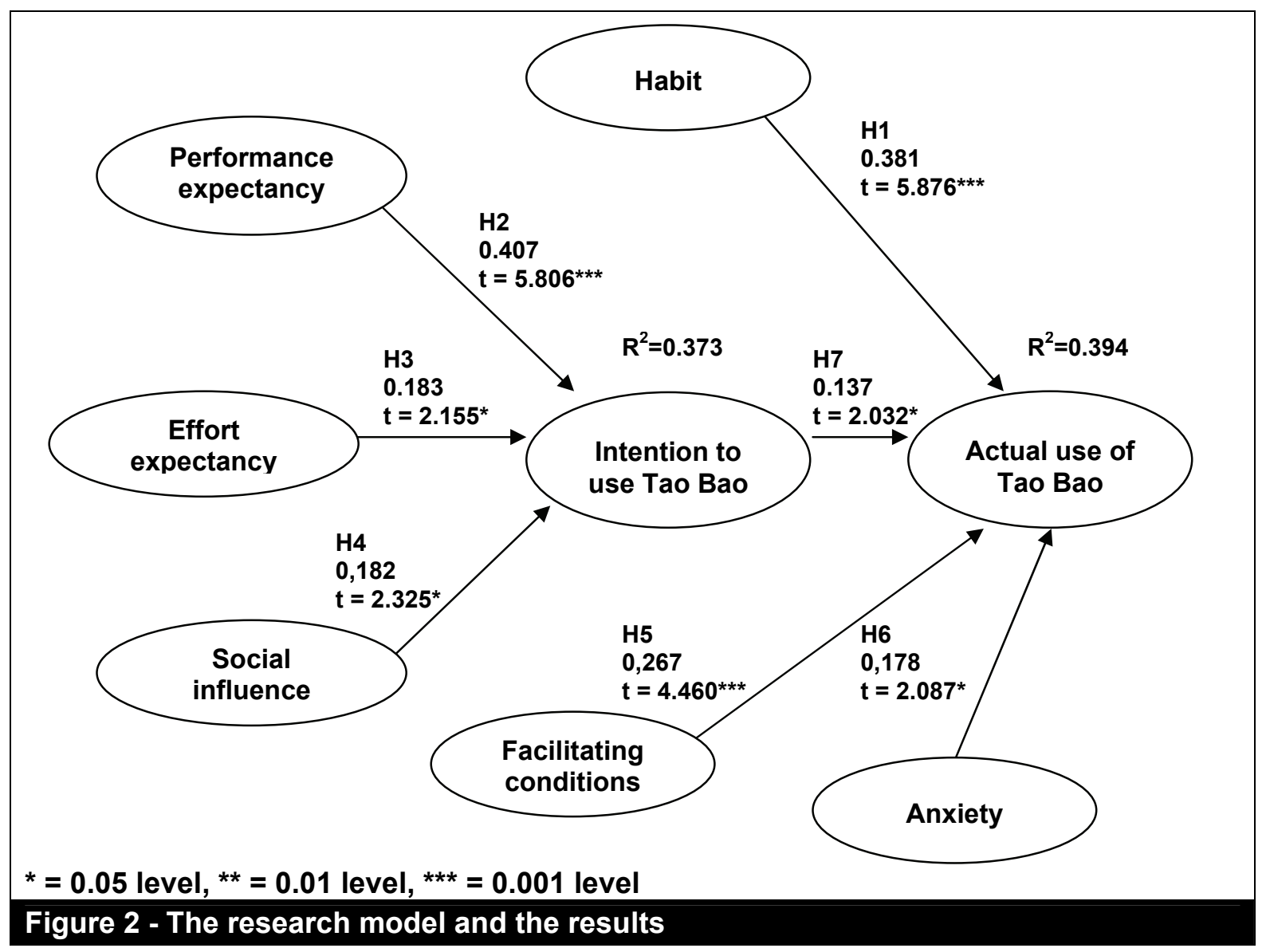




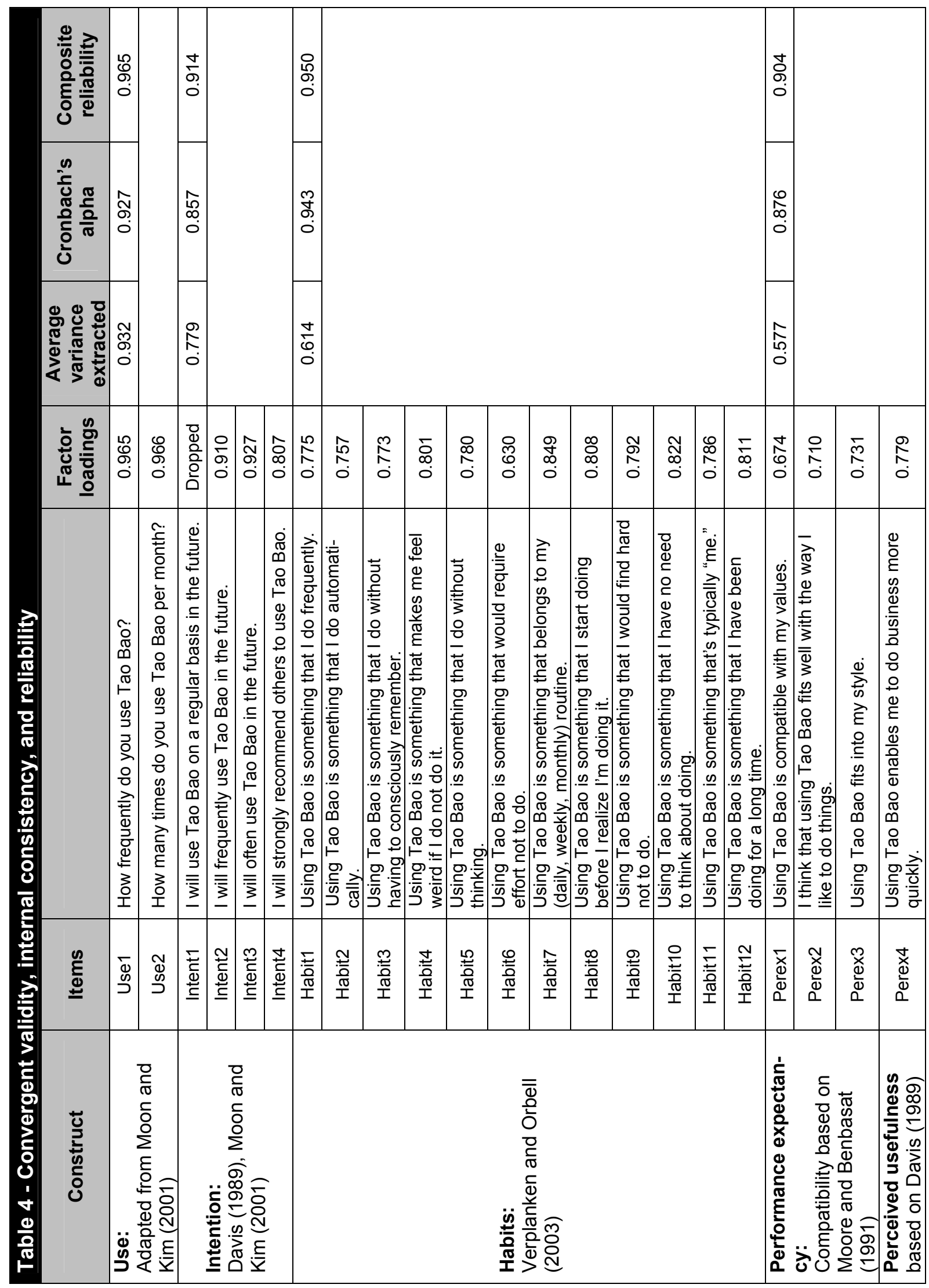




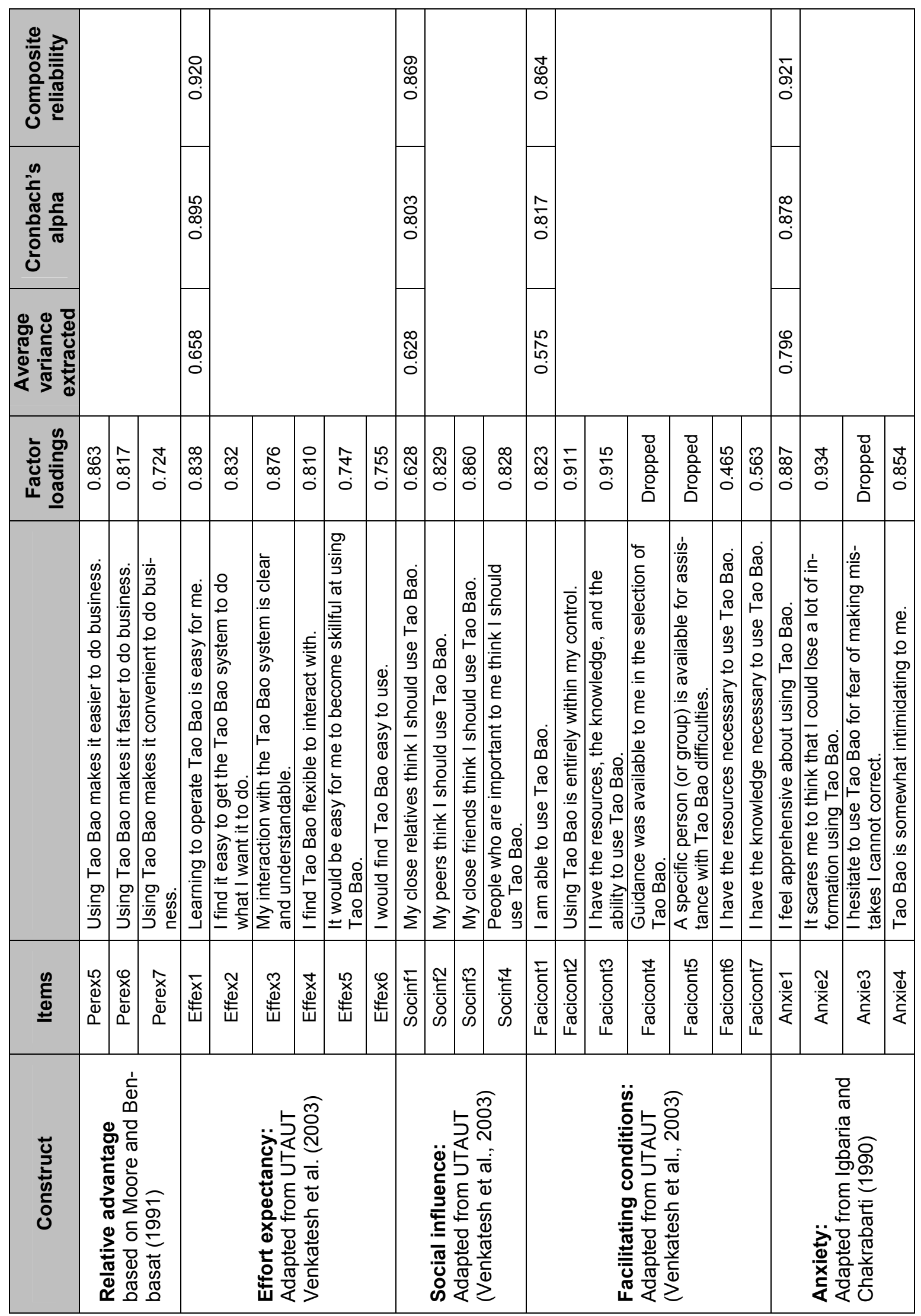


Integrating Habit into UTAUT: The Chinese eBay Case / Pahnila et al.

\begin{tabular}{|c|c|c|c|c|c|c|c|c|}
\hline Scale Items & Usage & Intent & Habit & Perex & Effexp & Socinf & Facicond & Anxie \\
\hline Use1 & 0.965 & 0.469 & 0.476 & 0.215 & 0.332 & 0.257 & 0.437 & 0.081 \\
\hline Use2 & 0.966 & 0.409 & 0.529 & 0.240 & 0.325 & 0.247 & 0.462 & 0.020 \\
\hline Intent2 & 0.459 & 0.910 & 0.568 & 0.490 & 0.407 & 0.268 & 0.402 & -0.138 \\
\hline Intent3 & 0.455 & 0.927 & 0.553 & 0.508 & 0.362 & 0.300 & 0.408 & -0.139 \\
\hline Intent4 & 0.277 & 0.807 & 0.394 & 0.475 & 0.433 & 0.384 & 0.432 & -0.119 \\
\hline Habit1 & 0.559 & 0.621 & 0.775 & 0.511 & 0.498 & 0.327 & 0.410 & -0.127 \\
\hline Habit2 & 0.467 & 0.553 & 0.757 & 0.619 & 0.477 & 0.196 & 0.404 & -0.212 \\
\hline Habit3 & 0.376 & 0.470 & 0.773 & 0.514 & 0.381 & 0.230 & 0.307 & -0.186 \\
\hline Habit4 & 0.369 & 0.391 & 0.801 & 0.442 & 0.351 & 0.173 & 0.223 & -0.165 \\
\hline Habit5 & 0.326 & 0.385 & 0.780 & 0.427 & 0.355 & 0.115 & 0.290 & -0.244 \\
\hline Habit6 & 0.328 & 0.279 & 0.630 & 0.281 & 0.106 & -0.078 & 0.107 & -0.102 \\
\hline Habit7 & 0.466 & 0500 & 0.849 & 0.504 & 0.350 & 0.180 & 0.283 & -0.154 \\
\hline Habit8 & 0.403 & 0.454 & 0.808 & 0.528 & 0.393 & 0.193 & 0.322 & -0.166 \\
\hline Habit9 & 0.325 & 0.399 & 0.792 & 0.417 & 0.325 & 0.129 & 0.249 & -0.238 \\
\hline Habit10 & 0.383 & 0.392 & 0.822 & 0.464 & 0.337 & 0.174 & 0.318 & -0.204 \\
\hline Habit11 & 0.300 & 0.332 & 0.786 & 0.382 & 0.270 & 0.063 & 0.185 & -0.197 \\
\hline Habit12 & 0.438 & 0.465 & 0.811 & 0.423 & 0.440 & 0.168 & 0.355 & -0.231 \\
\hline Perex1 & -0.087 & 0.432 & 0.362 & 0.674 & 0.266 & 0.159 & 0.168 & -0.175 \\
\hline Perex2 & -0.089 & 0.407 & 0.359 & 0.710 & 0.306 & 0.175 & 0.223 & -0.164 \\
\hline Perex3 & 0.014 & 0.371 & 0.414 & 0.731 & 0.302 & 0.205 & 0.150 & -0.134 \\
\hline Perex4 & 0.393 & 0.420 & 0.595 & 0.779 & 0.491 & 0.275 & 0.277 & -0.173 \\
\hline Perex5 & 0.367 & 0.452 & 0.522 & 0.863 & 0.461 & 0.216 & 0.348 & -0.117 \\
\hline Perex6 & 0.319 & 0.466 & 0.511 & 0.817 & 0.467 & 0.215 & 0.271 & -0.192 \\
\hline Perex7 & 0.296 & 0.390 & 0.396 & 0.724 & 0.473 & 0.311 & 0.314 & -0.095 \\
\hline Effex1 & 0.296 & 0.308 & 0.322 & 0.449 & 0.838 & 0.272 & 0.584 & -0.090 \\
\hline Effex2 & 0.210 & 0.346 & 0.324 & 0.432 & 0.832 & 0.240 & 0.512 & -0.275 \\
\hline Effex3 & 0.354 & 0.382 & 0.482 & 0.395 & 0.876 & 0.227 & 0.608 & -0.176 \\
\hline Effex4 & 0.290 & 0.343 & 0.334 & 0.472 & 0.810 & 0.321 & 0.532 & -0.095 \\
\hline Effex5 & 0.262 & 0.410 & 0.450 & 0.439 & 0.747 & 0.178 & 0.449 & -0.109 \\
\hline Effex6 & 0.235 & 0.379 & 0.348 & 0.359 & 0.755 & 0.252 & 0.456 & -0.141 \\
\hline Socinf1 & 0.084 & 0.168 & 0.237 & 0.157 & 0.145 & 0.631 & 0.174 & 0.234 \\
\hline Socinf2 & 0.116 & 0.226 & 0.020 & 0.228 & 0.210 & 0.829 & 0.138 & 0.425 \\
\hline Socinf3 & 0.288 & 0.338 & 0.190 & 0.331 & 0.292 & 0.860 & 0.246 & 0.367 \\
\hline Socinf4 & 0.259 & 0.337 & 0.229 & 0.183 & 0.272 & 0.828 & 0.193 & 0.246 \\
\hline Facicont1 & 0.422 & 0.364 & 0.158 & 0.221 & 0.429 & 0.256 & 0.823 & 0.060 \\
\hline Facicont2 & 0.465 & 0.406 & 0.377 & 0.226 & 0.572 & 0.228 & 0.911 & -0.038 \\
\hline Facicont3 & 0.403 & 0.446 & 0.318 & 0.298 & 0.595 & 0.260 & 0.915 & 0.022 \\
\hline Facicont6 & 0.140 & 0.311 & 0.394 & 0.328 & 0.412 & 0.030 & 0.465 & -0.209 \\
\hline Facicont7 & 0.178 & 0.247 & 0.412 & 0.388 & 0.544 & -0.042 & 0.563 & -0.374 \\
\hline Anxie1 & 0.030 & -0.155 & -0.306 & -0.230 & -0.140 & 0.419 & -0.040 & 0.887 \\
\hline Anxie2 & 0.061 & -0.164 & -0.236 & -0.204 & -0.210 & 0.380 & -0.088 & 0.934 \\
\hline Anxie4 & 0.037 & -0.071 & -0.089 & -0.097 & -0.111 & 0.269 & -0.012 & 0.854 \\
\hline
\end{tabular}




\section{The structural model}

The results of our study are shown in Figure 2 , which shows the estimated path coefficients and the significance of the path, indicated with asterisks. Tests of significance were performed using the bootstrap procedure. Standardized betas show that habit has a strong and significant influence on Tao Bao use ( $\beta=0.137)$.

Performance expectancy ( $\beta=0.407$ ), effort expectancy $(\beta=0.183)$, social influence $(B$ $=0.182)$, and facilitating conditions $(B=$ 0.267 ) have a significant influence on intention to use Tao Bao. Anxiety $(\beta=0.178)$ and intention ( $\beta=0.137$ ) have a significant influence on Tao Bao use. Overall, the research model accounts for $39.4 \%\left(R^{2}=0.394\right)$ of the variance in Tao Bao use and $37.3 \%\left(R^{2}\right.$ $=0.373)$ in terms of intention to use Tao Bao.

We assessed the impact of habit on UTAUT by comparing the difference in $R^{2}$ values in the UTAUT model with habit, and without habit (see Figure 2 and Figure 3 ). The difference in $\mathrm{R}^{2}$ was calculated by comparing the changes in variance in the model by using the formula $f^{2}=\left(R^{2}\right.$ Full model $\mathrm{R}^{2}$ Partial model $) /\left(1-\mathrm{R}^{2} \mathrm{Full}\right.$ model) (Chin et al., 2003). It is suggested that $f^{2}$ values of $0.02,0.15$, and 0.35 indicate small, medium, and large effect size, respectively (Cohen, 1988). In our case, the comparison of $R^{2}$ between the model in which habit has a direct effect and the model without habit show that the effect size was medium $\mathrm{f}^{2}=0.394-$ $0.299 /(1-0.394)=0.16$.

It is important to note that a small effect size does not imply an unimportant effect. In order to test more precisely the importance of the effect size, we applied a pseudo F-test statistic, multiplying $f^{2}$ by $(n-k-1)$, where $n$ is the sample size and $k$ is the number of independent constructs (Mathieson et al., 2001). The F-test value $(33.93, p \leq 0.000)$ shows that the UTAUT model and UTAUT model with habit's direct effects differ significantly from each other, indicating that a model including habit explains significantly more variance in actual use of Tao Bao than does the UTAUT model without habit.

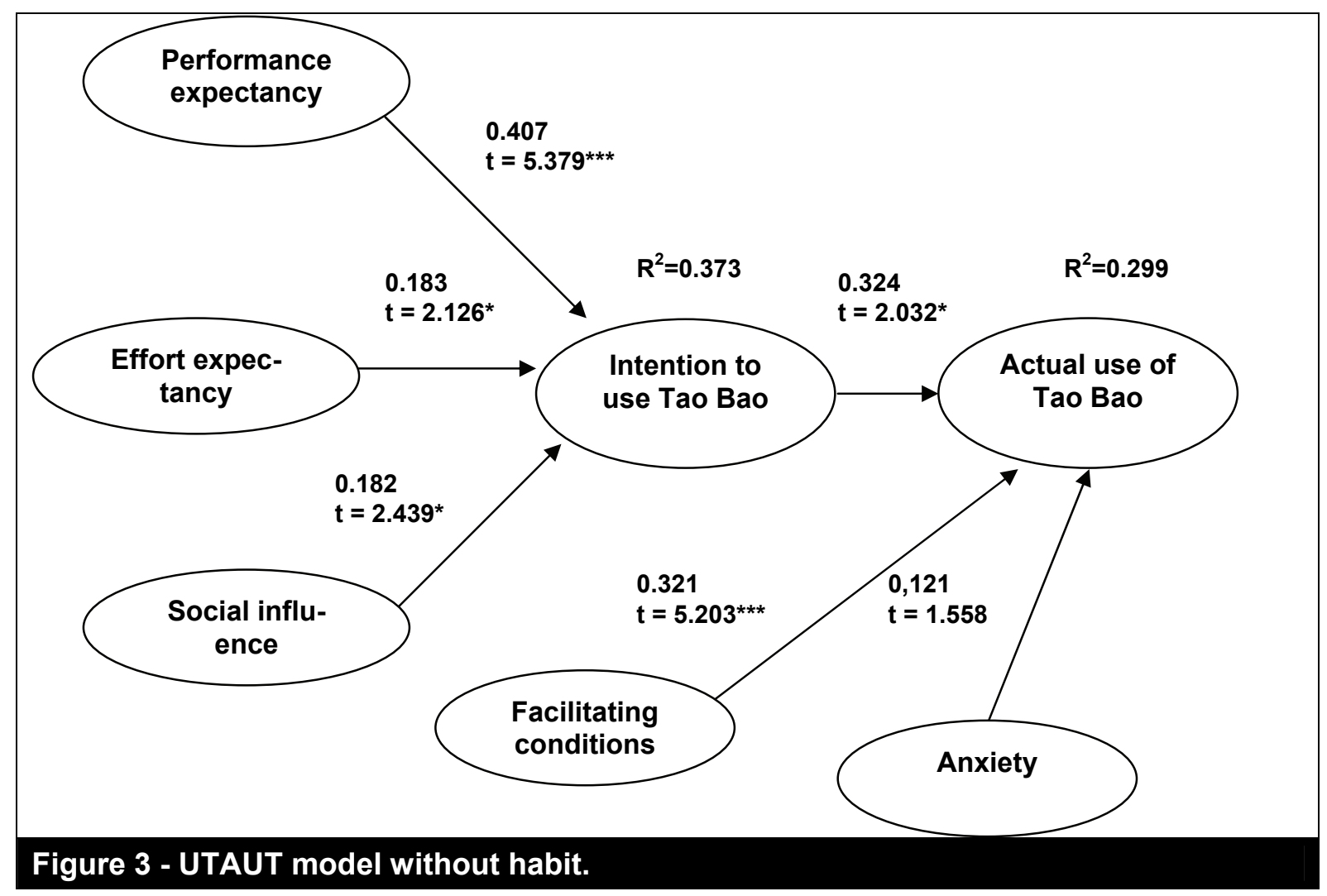


Integrating Habit into UTAUT: The Chinese eBay Case / Pahnila et al.

\section{Discussion}

UTAUT is a widely used and accepted model of IT acceptance and its predictive power is evident. It has been shown to be relatively adaptable in different cases and its efficiency is good. However, UTAUT does not include habitual behavior. Hence, the integration of habit into UTAUT is called for by Venkatesh et al. (2003) in order to further increase the explanatory power of UTAUT. Such a call for integrating habit into UTAUT is justified for theoretical and empirical reasons. Starting with the theoretical reasons, it is justified to include goaloriented habit into the reasoned-based UTAUT model, because the UTAUT model does not consider that the acceptance of technology or of a service can be due to the fact that users are accustomed (cf., habit) to using a particular system or service without assessing different aspects relating the use of the system or service. The justification for integrating habit with UTAUT is also empirical in nature, given the strong, supportive empirical evidence on habitual and automatic behavior in IS (Limayem et al., 2007) and social psychology (Verplanken and Orbell, 2003). Against this backdrop, we added habit to UTAUT. In that way, we extended UTAUT to include an important element that the UTAUT model lacks, namely, habitual behavior. We have found no previous studies that have incorporated habit into UTAUT.

First, as the main contribution of our study, our results show that habit has a significant impact on actual use of Tao Bao and habit significantly increases the explanatory value of the original UTAUT model. Our study also supports the findings of Verplanken and Orbell (2003) that habit predicts behavior; in our case, the behavior was the use of Tao Bao. In our study, we applied the self-report habit index by Verplanken and Orbell (2003). To the best of our knowledge, the self-report habit index has not yet been applied in the IS research field.

The second contribution of this study is that it tested UTAUT in a new context. The new context was Tao Bao.
Third, our results suggest that the effect of social influence on intention to use Tao Bao is significant. This finding, which is consistent with previous UTAUT research (Venkatesh et al., 2003), suggests that users create their behavior based on interactions with each other. To be more precise, Venkatesh et al. (2003) found that social influences are more likely to be salient to older workers, particularly women, in the early stages of experience. In our case, about $93 \%$ of the respondents were less than 22 years old.

Fourth, our results suggest that anxiety has a positive and significant effect on actual use of the system. This finding is inconsistent with the findings of Igbaria and livari (1995) and Compeau et al. (1999), among others. Our results indicate that apprehensiveness or fear toward the system may prevent its use. There are a number of explanations for our results. On the one hand, it could be that the users are afraid that they may lose important information; for example, credit-card information. Also, the users were unaware of how their personal information would be used, or the users were afraid that they could lose their money during Tao Bao transactions. On the other hand, anxiety is dependent on emotional and environmental aspects; thus, familiarity with the system also has an influence on anxiety. Also, it is difficult to say to what extent the effect of anxiety on actual behavior is linked to technology use itself or linked to the use of the Tao Bao application. It is easy to believe that those who are familiar with the use of Tao Bao are more likely to be habitual users. However, respondents feel apprehensive about using Tao Bao, which may indicate that respondents are not very experienced Tao Bao users.

Fifth, our results suggest that performance expectancy, which combines usefulness, compatibility, and the relative advantage aspects derived from Technology Acceptance Model (TAM) and Innovation of Diffusion research, is one of the most significant factors to have an effect on intention. This result implies that respondents appre- 
ciate Tao Bao, which is compatible with their lifestyle and values, and it enables them to do business quickly. Originally, Venkatesh et al. (2003) found the relationship insignificant. However, they found that the relationship is stronger for women, older workers, and those with limited experience.

Sixth, our findings indicate that effort expectancy, which consists of the perceived ease of use factor derived from TAM, is an important factor in the acceptance of IS. Perceived ease of use refers to "the degree to which a person believes that using a particular system would be free of effort" (Davis 1989, p. 320.). In TAM, the corresponding variable of perceived ease of use refers to internal constraints such as the match between the individual's capabilities and the skills required by the system. Thus, effort expectancy indicates that an application perceived to be easier to use than another is more likely to arouse positive intentions among the users.

Finally, our results suggest that facilitating conditions has a significant impact on actual use of Tao Bao. Facilitating conditions is affected by a user's access to resources and is not focused on technical issues or technical benefits; it indicates individuals' perceptions about themselves. The significance of facilitating conditions shows that respondents believe themselves to have the abilities necessary to use the system and that they have the ability to gain from the system.

Based on these findings, we next discuss our implications for research and practice, starting with the research implications.

\section{Implications for research}

We offer five implications for research on the basis of our findings. First, there is the need to carry out rigorous tests of UTAUT in different contexts and cultures. Regarding this issue, previous research has applied UTAUT in the Czech Republic, France, Greece, India, Malaysia, the Netherlands, New Zealand, Saudi Arabia, South Africa, the United Kingdom, the United States,
Thailand, Kuwait, and Saudi Arabia. The empirical studies testing UTAUT have mainly provided support for the model. There are, however, inconsistent findings among the empirical studies testing the UTAUT model. To start with, the results of Al-Gahtani (2006) and Al-Gahtani et al. (2007) differed from the findings of Venkatesh et al. (2003), both with and without interacting variables. Also, the effects of the age and experience of the moderators differed from the findings of Venkatesh et al. (2003). In both papers, the models were consistent with the Venkatesh et al. (2003) model. We see four possible explanations for the inconsistencies: the authors (a) applied UTAUT in different application domains (e.g., the use of online stock systems vs. knowledge management systems); (b) used different statistical techniques; (c) applied different levels of rigor in the use of the statistical techniques; or (d) collected data in different countries/cultures (e.g., the USA vs. Kuwait). As a step toward remedying this situation, rigorous empirical studies in different contexts and countries are needed in order to determine which of these reasons explains the inconsistent findings. Because characteristics of good "positivistic" theories include high levels of generality and testability (Farnworth, 1989), testing theories in different contexts is important not only to determine the generalizability of the theories to different contexts, but also to understand the limitations of the theories in different contexts. These, in turn, are sources for theory refinement, which leads us to the next implication for research.

Second, scholars need to examine whether we can further improve the explanatory power of UTAUT. Following this idea, given that only four studies (Neufeld et al., 2007; Wang and Yang, 2005; Zhou et al., 2010; Chen, 2011) tried to extend UTAUT with the intention of further increasing its explanatory power, we advise scholars not only to test UTAUT in different contexts and countries, but also to consider extending it in order to further increase its explanatory power. One possible avenue is to extend UTAUT to include values. The well-known theory in this 
Integrating Habit into UTAUT: The Chinese eBay Case / Pahnila et al.

area is the theory of motivational types of values by Schwartz (1992). Research in social psychology has successfully tested it in more than 200 countries (Schwartz, 1992).

The third research avenue for IT acceptance is related to theory development. This is not related to UTAUT in particular, or to the testing of any existing models and theories, but rather to the development of new theories. To be more precise, scholars could apply the grounded theory approach and investigate the topic of IT acceptance from a clean slate, without any theories or theory testing in mind. This means that scholars should examine IT acceptance through interviews, by asking IS users why they do or do not use the systems. The results could be compared with UTAUT and other IT-acceptance models and theories, and ideally, the interview results could lead to a new theory or model on IT acceptance (which could be further tested against generalizability in various contexts by using surveys, for example). This kind of qualitative approach could raise new insights around IT acceptance and lead to theory development in this area. It would also allow IT-acceptance research to move to the next level by obtaining a deeper understanding of the reasons why people use an IS and what ease of use really means, i.e., what makes a system easy to use. This level of information would be useful for IS developers. Our point here is that systems' developers may regard the findings of ITacceptance research to be common knowledge. For example, developers may intuitively know that systems should be easy to use, but they may not know how to make systems easy to use or which functionalities of the system make it easy to use. It is the latter aspect that we encourage scholars to pay attention to in future research. In addition to interviews, action research approaches would also be useful here, especially studies that would allow scholars and practitioners to build systems based on ITacceptance research and its theories. Such action research studies would allow scholars to refine these theories, or instances of the theories, based on user feedback on the system. Qualitative studies could also prompt IS design theories in terms of Walls et al. (1992) that would guide practitioners in determining how to design systems that are acceptable and sticky-that is, so that people continue to use them.

The fourth research avenue relates to the role of anxiety in IT acceptance. The significant influence of anxiety on actual behavior is an interesting finding. It is difficult to say to what extent the effect of anxiety on actual behavior is linked to technology use itself, or if it is linked to the use of the Tao Bao application. It is easy to believe that those who are familiar with the use of Tao Bao are more likely habitual users. However, respondents feel apprehensive about using Tao Bao, which may indicate that respondents are not very experienced Tao Bao users. A significant impact of habit and anxiety on the actual use of IS is an interesting finding for further research. A longitudinal study could answer the question as to what extent habits and previous experiences impact on the correlation between anxiety and actual online behavior. Such a study would be worthwhile, as it is important for the service providers to know whether anxiety against the use of online services is dependent on the technology or on the service itself, or if anxiety is more tied to profound personal traits.

Fifth, future research should examine the formation of habits. While previous research offers instruments to measure habits (Limayem et al., 2007; Verplanken and Orbell, 2003), it does not offer insights as to how exactly individuals develop habit. Also, further research could examine how the persuasive elements of the online-service context will affect the user's habitual patterns. In terms of online shopping, this is important because online retailers could focus their services more closely on those who have different habitual patterns. It would also be important to find out, for example, whether different changes, structural or layout changes, in online services have an influence on users' habitual patterns. 


\section{Implications for practice}

We would like to highlight five implications for practice based on our findings.

First, our results also suggest that the role of habit should be taken seriously when attempting to increase system use. Verplanken and Orbell (2003) suggest that habit is a psychological construct that has many facets, rather than simply defining habit as past behavioral frequency. Habitual behavior is not an automatic tendency; rather, it reflects prior satisfactory experiences, which enhance the tendency to repeat the same behavior in the future. Thus, prior positive experiences constitute a connection to future behavior. In order to establish habitual behavior among users of IS in practice, organizations should try to enhance the degree of behavioral control over the behavior. In the online-shopping context, habitual users are challenging for online service providers. Research has shown that strong-habit individuals demand less information and less compensatory choices than weak-habit individuals. Habitual behavior may also imply less motivation to search out information regardless of whether or not that information is unknown and important (Verplanken et al., 1997). This behavior differs from the behavior of experienced users, who are generally aware of many relevant choice alternatives (Verplanken et al., 1997). Those individuals who have certain habits may require gradual persuasion to adopt new ways of acting.

Second, our results suggest that effect expectancy reveals that extrinsic motivation is an important aspect in the formulation of usage intention. This finding indicates that if the system enables users to do business more quickly, and is consistent with the users' way of acting then the users will be more likely to accept the system.

The significance of effort expectancy on intention indicates that ease of use of the system is an important factor that affects intention to accept the system. Practitioners typically try to build systems that are easy to use and provide functional features to help users accomplish their tasks with minimal effort. As the results of this study confirm, features relating to easy access to service, successful functionality, and flexibility of the system are perceived to be important among online shoppers in planning purchases. The ease of use of websites is also enhanced by service providers who develop websites with interfaces that are easy to learn and match the user's mental model; that is, providing sites that have personalized features. This could help users to gain easier access to services and to gather information at lower cost.

The third implication for practice suggests that social influence needs to be taken seriously when attempting to improve systems' use by users. We found that social influence has a significant influence on intention. Generally speaking, young people are an important online-shopping client segment and, as our results indicate, the social environment encourages the intention to use online services. This sets a challenge for service providers to maintain successful relationships with, and to create positive experiences among the users. We suggest that service providers should recognize that both good and bad word-of-mouth experiences affect users' behavior and acceptance of the system, and hence that service providers should invest in order to keep the existing users of their systems happy.

Fourth, our findings on the significance of facilitating conditions suggest that respondents are, to a certain extent, confident that they can get along with the system. In other words, the facilitating conditions' beliefs indicate that the respondents rely on their capabilities, that they have enough knowledge of how to use Tao Bao, that they feel that they have enough resources, and that they have the capabilities to control Tao Bao use. The respondents' belief in their abilities to use the system's features is a positive sign for the designers and developers of the system. In a workplace setting, this also means that organizations should pay attention to the availability of training and resources. This is especially important when considering the rapid developmental speed of infor- 
Integrating Habit into UTAUT: The Chinese eBay Case / Pahnila et al.

mation technology. Systems and applications are in a state of continuous change; users may resist changes and reject the system if they do not believe in their ability to control the system.

Also, with respect to facilitating conditions, our results imply that online shoppers should pay attention to the availability of services, taking into consideration issues that facilitate the use of external factors such as the effective use of resources. On the other hand, service providers should take into consideration that they have adequate resources, including a reliable technological infrastructure and easy access to services. From the service providers' viewpoint, paying attention to facilitating conditions and understanding their importance is important. As Triandis (1979) suggests, even when the intentions are high and the habits are well established, there may be no behavior if the facilitating conditions are not favorable.

Fifth, our results indicated that anxiety influences users' intention to use Tao Bao. Anxiety is dependent on emotional and environmental aspects, which may affect the adoption of technology. Anxiety describes the individual's internal fear or phobia of making mistakes or causing damage when using computers. Our results imply that, although respondents appreciated that performance expectancy and effort expectancy issues were important in formulating usage intention, they were afraid to use the system. Thus, it could be that the system itself is not scary to use, but that the respondents are afraid of the economic decisions and purchases they intended to make. Based on these findings, we suggest that service providers pay attention to after-sales services and trust. User trust can be gained by ensuring that the organization has committed to a strict privacy policy, and that the provider tells the users explicitly that gathering user data should lead to improved services.

\section{Limitations of the study}

This study is subject to typical limitations that should be taken into consideration when interpreting the results. The target survey group was made up of university students, which may raise the question of external validity. Thus, using students as a surrogate may cause bias in the results, although it is suggested that Internet users are mostly highly educated. It is a common fact that students have been used both as surrogates and survey subjects in the information system research field. The question concerning students as surrogates in research has been controversial, depending on the research context, e.g., Barrier and Davis (1993) and $\mathrm{Li}$ and Kishore (2006). Gefen and Straub (2004) concluded in their research that there is no reason to believe that the average profile of university students does not represent typical purchasers of online products and services. The university context is not very different from the organizational context. Remus (1986) suggests that it is more acceptable to use a student population in studies relating to general issues, but not when examining specific issues, because the experience, expertise, or education level of students may bring into question the external validity and generalization of the results. Considering that many university students work parttime in organizations, that university students are not a homogenic group, and that they do not have to follow a particular professional code, as members of one profession would, we believe that that in our case the results may not differ significantly between university students and other types of users of the same age. Having said that, it could be that students prioritize different issues relating to, for example, effort expectancy, and perceived expectancy.

With respect to our sample's age distribution, in our case the majority of the respondents were male and less than 22 years old. It could be that younger people are more accustomed to online shopping than older people. For example, Venkatesh et al. (2003) found that social influences are more likely to be salient to older workers, particularly women, in the early stages of experience. Given this, the age of the re- 
spondents can be listed as a limitation.

Another limitation is that in our survey we used widely used intention items (e.g., "I will use..."), and the use items were based on the regularity and frequency of Tao Bao use. Taking into consideration that the survey we carried out was cross-sectional by nature, the relationship between intention and behavior may raise questions when interpreting the results of the study. One solution to avoid this is to study usage intention, habit, and actual behavior at different points in time.

The final limitation of our study is related to usage frequency of Tao Bao. Some of the respondents responded that they do not use Tao Bao at all, and we did not exclude that group from our analysis. The number of non-users was so limited that we were not able to reliably analyze the possible effects on the results of the study.

\section{Conclusions}

IT acceptance is a well-studied topic in IS literature. Perhaps the leading theory in the field is UTAUT, which was developed by synthesizing eight technology-acceptance models. In order to further increase the explanatory power of UTAUT, it has been suggested that habit should be integrated into UTAUT. Despite this, we found no studies that had carried this out. As a step in remedying this gap in the literature, we first developed such an integrated model and then tested it empirically $(N=180)$. Our results supported the integration of habit into UTAUT. The extended UTAUT offers better explanatory value than UTAUT without habit. We put forward a research agenda for future research with five research streams and five implications for practice based on our findings.

\section{Footnotes}

\footnotetext{
To our knowdelege, this is the first paper that applies the self-report habit index by Verplanken and Orbell (2003) in IS. Previous research in IS has applied an alternative account of habit by Limayem and his colleagues (Cheung and Limayem, 2005; Limayem and Hirt, 2003; Limayem et al., 2004; Limayem et al., 2007).
}

\section{References}

Ajzen, I. (2002) Perceived Behavioral Control, Self-Efficacy, Locus Of Control, And The Theory Of Planned Behavior. Journal Of Applied Social Psychology, 32, 1-20.

Akers, R. L. \& Sellers, C. S. (2004) Criminological Theories: Introduction, Evaluation, And Application, Los Angeles Roxbury Publishing.

Alawadhi, S. \& Morris, A. (2008) The Use Of The Utaut Model In The Adoption Of E-Government Services In Kuwait. Proceedings Of The 41st Hawaii International Conference On System Sciences. Hawaii.

Al-Gahtani, S. S. (2006) Information Technology Adoption, The Roadmap To Sustainable Development: Examining Three Models. 18th National Computer Conference Information Technology And Sustainable Development.

Al-Gahtani, S. S., Hubona, G. S. \& Jijie, W. (2007) Information Technology (It) In Saudi Arabia: Culture And The Acceptance And Use Of It. Information \& Management, 44, 681-691.

Al-Qeisi, K. I. (2009) Analyzing The Use Of Utaut Model In Explaining An Online Behaviour: Internet Banking Adoption. Department Of Marketing And Branding. London, Brunel University.

Al-Shafi, S., Weerakkody, V. \& Janssen, M. (2009) Investigating The Adoption Of Egovernment Services In Qatar Using The Utaut Model. American Conference On Information Systems (Amcis).

Bailey, J. E. \& Pearson, S. W. (1983) Development Of $A$ Tool For Measuring And Analysing Computer User Satisfaction. Management Science, 29, 530-545.

Boudreau, M.-C. \& D. Gefen, E. A. (2001) Validation In Information Systems 
Integrating Habit into UTAUT: The Chinese eBay Case / Pahnila et al.

Research: A State-Of-The-Art Assessment. Mis Quarterly, 25, 1-16.

Brug, J., De Vet, E., De Nooijer, J. \& Verplanken, B. (2006) Predicting Fruit Consumption: Cognitions, Intention, And Habits. Journal Of Nutritional Education Behavior 38, 73-81.

Carlsson, C., Joanna, C., Hyvönen, K., Puhakainen, J. \& Walden, P. (2006) Adoption Of Mobile Devices/Services - Searching For Answers With The Utaut. Proceedings Of The 39th Hawaii International Conference On System Sciences. Hawaii.

Chen, J.-L. (2011) The Effects Of Education Compatibility And Technological Expectancy On E-Learning Acceptance. Computers \& Education, 57, 15011511.

Cheung, C. M. K. \& Limayem, M. (2005) The Role Of Habit In Information Systems Continuance: Examining The Evolving Relationship Between Intention And Usage. Proceedings Of The Twenty-Sixth International Conference On Information Systems. Las Vegas.

Cheung, W., Chang, M. K. \& Lai, V. S. (2000) Prediction Of Internet And World Wide Web Usage At Work: A Test Of An Extended Triandis Model. Decision Support Systems, 30, 83100.

Chin, W. \& Newsted, P. (1999b) Structural Equation Modeling Analysis With Small Samples Using Partial Least Squares. In Hoyle, R. (Ed.) Statistical Strategies For Small Sample Research. Thousand Oaks, Ca, Sage Publications.

Chin, W. W., Salisbury, W. D., W, P. A. \& Stollak, M. J. (1999a) Perceived Cohesion In Small Groups: Adapting And Testing The Perceived Cohesion Scale In A Small-Group Setting. Small Group Research, 30, 751-766.
Cohen, J. (1988) Statistical Power Analysis For The Behavioral Sciences, Hillsdale, $\mathrm{Nj}$, Hillsdale, $\mathrm{Nj}$ : Lawrence Erlbaum.

Compeau, R., Deborah, Higgins, A., Christopher \& Huff, S. (1999) Social Cognitive Theory And Individual Reactions To Computing Technology: A Longitudinal Study. Mis Quarterly, 23, 145-158.

Davis, D. F. (1989) Perceived Usefulness, Perceived Ease Of Use, And User Acceptance Of Information Technology. Mis Quarterly, 13, 319-340.

Davis, F. D. (1993) User Acceptance Of Information Technology: System Characteristics, User Perceptions And Behavioral Impacts. International Journal Of Man-Machine Studies, 38, 475-487.

Farnworth, M. (1989) Theory Integration Versus Model Building, Albany: State University Of New York Press.

Fornell, C. \& Larcker, D. (1981) Evaluating Structural Equation Models With Unobservable Variables And Measurement Error. Journal Of Marketing Research, 18, 39-50.

Gefen, D. \& Straub, D. W. (2004) Consumer Trust In B2c E-Commerce And The Importance Of Social Presence: Experiments In E-Products And EServices. Omega, 32, 407-424.

Guinea, A. O. \& Markus, L. M. (2009) Why Break The Habit Of A Lifetime? Rethinking The Roles Of Intention, Habit, And Emotion In Continuing Information Technology Use. Mis Quarterly, 33, 433-444.

Hair, J. F. J., Anderson, R. E., Tatham, R. L. \& Black, W. C. (1998) Multivariate Data Analysis, Upper Saddle River, New Jersey, Prentice Hall Inc.

Hair, J. F. J., Black, W. C., Babin, B. J., Anderson, R. E. \& Tatham, R. L. (2006) 
Multivariate Data Analysis, Pearson Prentice Hall.

Igbaria, M. \& Chakrabarti, A. (1990) Computer Anxiety And Attitudes Towards Microcomputer Use. Behaviour \& Information Technology, 9, 229-241.

Igbaria, M. \& livari, J. (1995) The Effects Of Self-Efficacy On Computer Usage. Omega. The International Journal Of Management Science, 23, 587-605.

Isabelle, B. \& Sandrine, O.-H. (2009) Towards An Understanding Of Knowledge Management Systems Utaut Revisited. Americas Conference On Information Systems (Amcis).

Kijsanayoting, B., Pannarunothai, S. \& Speedie, S. M. (2009) Factors Influencing Health Information Technology Adoption In Thailand'S Community Health Centers: Applying The Utaut Model. International Journal Of Medical Informatics, 78, 404-416.

Kim, S. S., Malhotra, N. K. \& Narasimhan, S. (2005) Two Competing Perspectives On Automatic Use: A Theoretical And Empirical Comparison. Information Systems Research, 16, 418432.

Kim, Y. \& Srivastava, J. (2007) Impact Of Social Influence In E-Commerce Decision Making. Icec'07. Minneapolis, $\mathrm{Mn}$, Usa, Acm.

Kleijnen, M., De Ruyter, K. \& Wetzels, M. (2007) An Assessment Of Value Creation In Mobile Service Delivery And The Moderating Role Of Time Consciousness. Journal Of Retailing, 83, 33 - 46.

Li, J. P. \& Kishore, R. (2006) How Robust Is The Utaut Instrument? A Multigroup Invariance Analysis In The Context Of Acceptance And Use Of Online Community Weblog Systems. Sigmis-Cpr April 13-15, Claremont, California, Usa.
Limayem, M. \& Hirt, S. G. (2003) Force Of Habit And Information Systems Usage: Theory And Initial Validation. Journal Of The Association For Information Systems, 4, 65-97.

Limayem, M., Hirt, S. G. \& Cheung, C. M. K. (2007) How Habit Limits The Predictive Power Of Intention: The Case Of Information Systems Continuance Mis Quarterly, 36, 705-737.

Limayem, M., Khalifa, M. \& Chin, W. W. (2004) Factors Motivating Software Piracy: A Longitudinal Study. leee Transactions On Engineering Management, 51, 414-425.

Limayem, M., Khalifa, M. \& Frini, A. (2000) What Makes Consumers Buy From Internet? A Longitudinal Study Of Online Shopping. leee Transactions On Systems, Man, And Cybernetics - Part A: Systems And Humans, 30, 421 - 432.

Malhotra, N. K., Kim, S. S. \& Patil, A. (2006) Common Method Variance In Is Research: A Comparison Of Alternative Approaches And A Reanalysis Of Past Research. Management Science, 52, 1865-1883.

Marchewka, J. T., Chang, L. \& Kostiwa, K. (2007) An Application Of The Utaut Model For Understanding Student Perceptions Using Course Management Software. Communications of The lima, 7, 93-104.

Moon, J.-W. \& Kim, Y.-G. (2001) Extending The Tam For A World-Wide-Web Context. Information \& Management, 38, 217-230.

Morahan-Martin, J. \& Schumacher, P. (2000) Incidence And Correlates Of Pathological Internet Use Among College Students. Computers In Human Behavior, 16, 13 - 29.

Networkworld (2010) Chinese Ebay Rival Taobao To Share Wide Transaction Data. 
Integrating Habit into UTAUT: The Chinese eBay Case / Pahnila et al.

Neufeld, D. J., Dong, L. \& Higgins, C. (2007) Charismatic Leadership And User Acceptance Of Information Technology. European Journal Of Information Systems, 16, 494-510.

Nunnally, J. C. (1978) Psychometric Theory, Macgraw-Hill.

Ortiz De Guinea, A. \& Markus, L. M. (2009) Why Break The Habit Of A Lifetime? Rethinking The Roles Of Intention, Habit, And Emotion In Continuing Information Technology Use. Mis Quarterly, 33, 433 - 444.

Oshlyansky, L., Cairns, P. \& Thimbleby, H. (2008) Validating The Unified Theory Of Acceptance And Use Of Technology (Utaut) Tool Cross-Culturally. Proceedings Of The 21st British Hci Group Annual Conference On Hci. People And Computers Xxi: Hci...But Not As We Know It - Volume 2. University Of Lancaster, United Kingdom, British Computer Society.

Park, J., Yang, S. \& Lehto, X. (2007) Adoption Of Mobile Technologies For Chinese Consumers. Journal Of Electronic Commerce Research, 8, 196-206.

Podsakoff, P. M., Mackenzie, S. B. \& Podsakoff, N. P. (2003) Common Method Biases In Behavioral Research: A Critical Review Of The Literature And Recommended Remedies. Journal Of Applied Psychology, 88, 879-903.

Remus, W. (1986) Graduate Students As Surrogates For Managers In Experiments On Business Decision Making. Journal Of Business Research, 14, 19-25.

Ringle, C. \& Wende, S. (2005) Smartpls 2.0 (M3) Beta. Hamburg.

Rogers, E. M. (1995) Diffusion Of Innovations, New York, The Free Press.

Schwartz, S. H. (1992) Universals In The Content And Structure Of Values:
Theoretical Advances And Empirical Tests In 20 Countries. In Zanna, M. (Ed.) Advances In Experimental Social Psychology. New York, Academic Press

Sievert, M. E., Albritton, R. L., Roper, P. \& Clayton, N. (1988) Investigating Computer Anxiety In An Academic Library. Information Technology And Libraries., 7, 243-252.

Simon, J. \& Bruce, P. (1991) Resampling: A Tool For Everyday Statistical Work. Change: New Directions For Statistics And Computing, 4, 22 - 32.

Straub, D. W. (1989) Validating Instruments In Mis Research. Mis Quarterly, 13, 147-169.

Taylor, S. \& Todd, P. A. (1995b) Assessing It Usage: The Role Of Prior Experience. Mis Quarterly, 561-568.

Tiwana, A. \& Konsynski, B. (2009) Complementarities Between Organizational It Architecture And Governance Structure. Information Systems Research, 21, 288-304.

Thornberry, T. P. (1989) Reflections On The Advantages And Disadvantages Of Theoretical Integration. In Messner, S. F., Krohn, M. D. \& Liska, A. E. (Eds.) Theoretical Integration In The Study Of Deviance And Crime. Albany, State University Of New York Press.

Tornatzky, L. G. \& Klein, K. J. (1982) Innovation Characteristics And Innovation Adoption-Implementation: A Meta-Analysis Of Findings. leee Transactions On Engineering Management, 29, 28-45.

Triandis, H. C. (1980) Values, Attitudes, And Interpersonal Behavior. Nebraska Symposium On Motivation 1979. University Of Nebraska Press, Lincoln.

Venkatesh, V., Morris, M. G. \& Ackerman, M. S. (2000) A Longitudinal Field In- 
vestigation Of Gender Differences In Individal Techology Adoption Decision-Making Processes. Organizational Behavior And Human Decision Processes, 83, 33-60.

Venkatesh, V., Morris, M. G., Davis, G. B. \& Davis, F. D. (2003) User Acceptance Of Information Technology: Toward A Unified View. Mis Quarterly, 27, 425-478.

Venkatesh, V., Brown, S. A., Maruping, L. M. \& Bala, H. (2008) Predicting Different Conceptualizations Of System Use: The Competing Roles Of Behavioral Intention, Facilitating Conditions, And Behavioral Expectation. Mis Quarterly, 32, 483-502.

Verplanken, B. (2006) Beyond Frequency: Habit As A Mental Construct. British Journal Of Social Psychology, 45, 639-656.

Verplanken, B., Aarts, H. \& Knippenberg Van, A. (1997) Habit, Information Acquisition, And The Process Of Making Travel Mode Choices. European Journal Of Social Psychology, $27,539-560$.

Verplanken, B. \& Orbell, S. (2003) Reflections On Past Behavior: A SelfReport Index Of Habit Strength. Journal Of Applied Social Psychology, 33, 1313-1330.
Verplanken, B. \& Aarts, H. (1999) Habit, Attitude, And Planned Behavior: Is Habit An Empty Construct Or An Interesting Case Of Goal-Directed Automaticity? European Review Of Social Psychology, 10, 101-134.

Verplanken, B. \& Melvik, O. (2008) Predicting Habit: The Case Of Physical Exercise," Psychology Of Sport And Exercise. Psychology Of Sport And Exercise, 9, 15-26.

Walls, J. G., Wildmeyer, G. R. \& El Sawy, O. A. (1992) Building An Information Systems Design Theory For Vigilant Eis. Information Systems Research, 3, 36-59.

Walsh, I. (2010) What Amazon Can Learn From Taobao, The Largest Chinese Ecommerce Portal. Http://Www.Ivanwalsh.Com/China/W hat-Amazon-Can-Learn-FromTaobao-The-Largest-ChineseEcommerce-Portal/4041/.

Wang, H.-I. \& Yang, H.-L. (2005) The Role Of Personality Traits In Utaut Model Under Online Stocking. Contemporary Management Research, 1, 6982.

Zhou, T., Lu, Y. \& Wang, B. (2010) Integrating Ttf And Utaut To Explain Mobile Banking User Adoption. Computers In Human Behavior, 26, 760-767. 
Integrating Habit into UTAUT: The Chinese eBay Case / Pahnila et al.

\begin{abstract}
About Authors
Seppo Pahnila is from University of Oulu at Finland. He received his Ph.D. in information processing science from University of Oulu in Finland. He is presently serving as a senior researcher in Information Systems Security Research Center at University of Oulu in Finland. His research interests include information systems security, IS security policy compliance, Web information systems and electronic commerce. He has published in the information systems and business management journals including IEEE Computer, European Journal of Information Systems, Communications of the ACM, Behavior \& Information Technology, International Journal of Bank Marketing and Internet Research Journal.
\end{abstract}

Mikko Siponen is a $s$ a Professor and the Director of the IS Security Research Centre in the Department of Information Processing Science at the University of Oulu, Finland. $\mathrm{He}$ is also a Vice-Head of the department. He holds a Doctor of Social Sciences in Philosophy degree from the University of Joensuu, Finland, and a Ph.D. degree in Information Systems. In addition to his 70 conference articles, Dr. Siponen has published 39 articles in journals such as MIS Quarterly, Journal of the Association for Information Systems, European Journal of Information Systems, Information \& Organization, Information Systems Journal, Information \& Management, Journal of Organizational and End User Computing, Commu- nications of the ACM, IEEE Computer, and IEEE IsT Professional. Dr. Siponen has secured over $€ 4$ million of research funding from corporations and numerous funding bodies. The Finnish Funding Agency for Technology and Innovation ranked the IS Security Research Centre that Dr. Siponen established and lead as one of the top ICT research groups in Finland. Dr. Siponen has served as Senior Editor for ICIS and ECIS three times, and he was a Guest SE and Guest AE for the MIS Quarterly. Currently, he sits on the editorial boards of EJIS and CAIS. His research interests include IS security, IS development, computer ethics, and philosophical aspects of IS.

Xiaosong Zheng is a lecturer in Information Management at Sydney Institute of Language and Commerce, Shanghai University, P.R.China. He received a Ph.D. in Information Processing Science from University of Oulu in Finland in 2007. He also holds an M.Sc. in Economics and Business Administration from Hanken Swedish School of Economics and Business Administration in Finland and an M.Eng. in Electrical Engineering from Swinburne University of Technology in Australia. He has published in several international journals such as Computing \& Informatics and Information Technologies \& Control. His current research interests include IS security, IS management, electronic business and mobile business, user-centered design etc. 